\title{
The Role and Use of Non-Saccharomyces Yeasts in Wine Production
}

\author{
N.P. Jolly ${ }^{1 *}$, O.P.H. Augustyn ${ }^{1}$ and I.S. Pretorius ${ }^{2 * *}$
}

(1) ARC Infruitec-Nietvoorbij***, Private Bag X5026, 7599 Stellenbosch, South Africa.

(2) Institute for Wine Biotechnology, Department of Viticulture \& Oenology, Stellenbosch University, Private Bag X1, 7602 Matieland (Stellenbosch), South Africa.

Submitted for publication: September 2005

Accepted for publication: April 2006

Key words: Non-Saccharomyces, yeasts, vineyards, cellars, fermentation, wine.

\begin{abstract}
The contribution by the numerous grape-must-associated non-Saccharomyces yeasts to wine fermentation has been debated extensively. These yeasts, naturally present in all wine fermentations, are metabolically active and their metabolites can impact on wine quality. Although often seen as a source of microbial spoilage, there is substantial contrary evidence pointing to a positive contribution by these yeasts. The role of non-Saccharomyces yeasts in wine fermentation is therefore receiving increasing attention by wine microbiologists in Old and New World wine producing countries. Species that have been investigated for wine production thus far include those from the Candida, Kloeckera, Hanseniaspora, Zygosaccharomyces, Schizosaccharomyces, Torulaspora, Brettanomyces, Saccharomycodes, Pichia and Williopsis genera. In this review the use and role of non-Saccharomyces yeast in wine production is presented and research trends are discussed.
\end{abstract}

\section{INTRODUCTION}

Wine is the product of a complex biological and biochemical interaction between grapes (grape juice) and different microorganisms (fungi, yeasts, lactic acid bacteria and acetic acid bacteria) and the mycoviruses and bacteriophages affecting them (Fleet, 2003). The process starts in the vineyard, continues through fermentation and maturation, and concludes at packaging. It is affected by the various viticultural and oenological practices available to the grape-grower and winemaker, respectively (Regueiro et al., 1993). Of the microorganisms involved, it is the yeasts that play the most important role; they conduct the alcoholic fermentation (conversion of grape sugar to ethanol and $\mathrm{CO}_{2}$ ). Furthermore, although wine flavour is directly determined by grape variety, yeasts also affect wine flavour and quality by the production and excretion of metabolites during growth and through autolysis (Fleet, 1993, 2003; Lambrechts \& Pretorius, 2000; Swiegers \& Pretorius, 2005; Swiegers et al., 2005). In some instances, yeasts can also act as spoilage organisms during wine production (including maturation) and after packaging (Loureiro \& Malfeito-Ferreira, 2003). Yeasts present during fermentation are derived from grapes and the vineyard, the equipment used in the cellar, cellar surfaces and external sources such as selected cultures that are added to facilitate the fermentation process.

Since 1866, when Louis Pasteur first elucidated the bio-conversion of grape juice into wine, this complex process and the role of the yeast therein has been studied extensively. Yet, more than 130 years later, there are many areas that are still not well understood (Pretorius, 2000). This is especially the case for the roles of the numerous non-Saccharomyces yeasts normally associated with grape must and wine. These yeasts, naturally present in all wine fermentations to a greater or lesser extent, are metabolically active and their metabolites can impact on wine quality. While they were originally seen as a source of microbial related problems in wine production, winemakers, especially in Old World countries, saw indigenous yeasts as integral to the authenticity of their wines as these yeasts impart distinct regional and other desirable characteristics (Amerine et al., 1972; Jackson, 1994). Evidence supporting this view has been published (Fleet, 1990; Heard, 1999) and the role of the non-Saccharomyces yeasts in wine fermentation is receiving increasingly more attention by wine microbiologists in both Old and New World wine-producing countries.

\section{YEAST CLASSIFICATION}

Yeasts can be defined as unicellular fungi, either ascomycetous or basidiomycetous, that have vegetative states which predominantly reproduce by budding or fission and which do not form their sexual states within or on a fruiting body (Kurtzman \& Fell, 1998a).

Current taxonomies recognise 100 genera comprising more than 700 species (Kurtzman \& Fell, 1998b), of which approximately 20 are relevant to winemaking (Fleet, 1993). Yeast genera, with those non-Saccharomyces yeasts relevant to winemaking indicated in bold type, are listed in Table 1.

Rules for taxonomy of yeasts fall under the authority of the International Code of Botanical Nomenclature (Greuter et al., 1994). Publication of new species must include a description of essential characteristics, as well as a diagnosis that distinguishes

\footnotetext{
* Corresponding author: E-mail address: jollyn@arc.agric.za

** Present address: The Australian Wine Research Institute, P.O. Box 197, Glen Osmond, Adelaide, SA 5064, Australia.

***The Fruit, Vine and Wine Institute of the Agricultural Research Council
} 
the taxon from previously described species. Names of taxa must be given in Latin or modified in such a way that they follow the rules of Latin derivation, including appropriate designations.

The first level of yeast classification is based on the lack of a sexual phase during the life cycle (Deuteromycotina) or aspects of the sexual phase (Ascomycotina and Basidiomycotina). Further taxonomic subdivisions (orders, families, genera and species) are based on morphological, physiological, biochemical and genetic properties (Kreger-van Rij, 1984; Kurtzman \& Fell, 1998 b) that are elucidated by conducting 55 to 70 tests. Many of these tests can be used individually to characterise a selection of yeasts.

Some yeasts are found as a sexual (teleomorphic) type and produce ascospores. A similar form of the same yeast is the asexual (anamorphic) type that does not form ascospores. To complicate matters, the ability to form ascospores can be lost during longterm storage (Yarrow, 1998; M. Th. Smith, personal communication, 2000). Sporulation is also difficult to induce for some yeasts. Whether a newly isolated yeast is subsequently identified as teleomorphic or anamorphic can therefore largely depend on the time lapsed between isolation and identification as well as adherence to methodology. This can lead to confusion when authors report on isolates as essentially the same yeast species, but refer to them by different names. If any uncertainty exists in determining sporulation it is therefore preferable to use the anamorphic name where applicable. Some of the more commonly encountered anamorphic yeasts and their teleomorphic counterparts in must and wine are given in Table 2.

\section{TABLE 1}

A list of yeast genera ${ }^{1}$ according to Kurtzman \& Fell (1998b).

\begin{tabular}{|c|c|c|c|}
\hline $\begin{array}{l}\text { Teleomorphic } \\
\text { ascomycetous genera } \\
\text { (Ascomycotina) }\end{array}$ & $\begin{array}{l}\text { Anamorphic } \\
\text { ascomycetous genera } \\
\text { (Deuteromycotina) }\end{array}$ & $\begin{array}{l}\text { Teleomorphic } \\
\text { heterobasidio-mycetous genera } \\
\text { (Basidiomycotina) }\end{array}$ & $\begin{array}{l}\text { Anamorphic } \\
\text { heterobasidio-mycetous genera } \\
\text { (Basidiomycotina) }\end{array}$ \\
\hline Ambrosiozyma & Aciculoconidium & Agaricostilbum & Bensingtonia \\
\hline Arxiozyma & Arxula & Bulleromyces & Bullera \\
\hline Ascoidea & Blastobotrys & Chionosphaera & Cryptococcus \\
\hline Babjevia & Botryozyma & Cystofilobasidium & Fellomyces \\
\hline Cephaloascus & Brettanomyces & Erythrobasidium & Hyalodendron \\
\hline Citeromyces & Candida & Fibulobasidium & Itersonilia \\
\hline Clavispora & Geotrichum & Filobasidiella & Kockovaella \\
\hline Coccidiascus & Kloeckera & Filobasidium & Kurtzmanomyces \\
\hline Cyniclomyces & Lalaria & Holtermannia & Malassezia \\
\hline Debaryomyces & Myхоzуma & Leucosporidium & Moniliella \\
\hline Dekkera & Oosporidium & Mrakia & Phaffia \\
\hline Dipodascopsis & Saitoella & Rhodosporidium & Pseudozyma \\
\hline Dipodascus & Schizoblastosporion & Sirobasidium & Reniforma \\
\hline Endomyces & Sympodiomyces & Sporidiobolus & Rhodotorula \\
\hline Eremothecium & Trigonopsis & Sterigmatosporidium & Sporobolomyces \\
\hline Galactomyces & & Tilletiaria & Sterigmatomyces \\
\hline Hanseniaspora & & Tremella & Sympodiomycopsis \\
\hline Issatchenkia & & Trimorphomyces & Tilletiopsis \\
\hline Kluyveromyces & & Xanthophyllomyces & Trichosporon \\
\hline Lipomyces & & & Trichosporonoides \\
\hline Lodderomyces & & & Tsuchiyaea \\
\hline \multicolumn{4}{|l|}{ Metschnikowia } \\
\hline \multicolumn{4}{|l|}{ Nadsonia } \\
\hline \multicolumn{4}{|l|}{ Pachysolen } \\
\hline \multicolumn{4}{|l|}{ Pichia } \\
\hline \multicolumn{4}{|l|}{ Protomyces } \\
\hline \multicolumn{4}{|l|}{ Saccharomyces } \\
\hline \multicolumn{4}{|l|}{ Saccharomycodes } \\
\hline \multicolumn{4}{|l|}{ Saccharomycopsis } \\
\hline \multicolumn{4}{|l|}{ Saturnispora } \\
\hline \multicolumn{4}{|l|}{ Schizosaccharomyces } \\
\hline \multicolumn{4}{|l|}{ Sporopachydermia } \\
\hline \multicolumn{4}{|l|}{ Stephanoascus } \\
\hline \multicolumn{4}{|l|}{ Torulaspora } \\
\hline \multicolumn{4}{|l|}{ Wickerhamia } \\
\hline \multicolumn{4}{|l|}{ Wickerhamiella } \\
\hline \multicolumn{4}{|l|}{ Williopsis } \\
\hline \multicolumn{4}{|l|}{ Yarrowia } \\
\hline \multicolumn{4}{|l|}{ Zygoascus } \\
\hline \multicolumn{4}{|l|}{ Zygosaccharomyces } \\
\hline Zygozyma & & & \\
\hline
\end{tabular}

\footnotetext{
${ }^{1}$ Non-Saccharomyces genera that can be encountered in vineyards, on winery surfaces, in grape musts and/or in wine are indicated in bold type.
} 
TABLE 2

Anamorphs, teleomorphs and synonyms of some of the non-Saccharomyces yeasts in the Ascomycetous genera encountered in wine fermentations (Kurtzman \& Fell, 1998b).

\begin{tabular}{|c|c|c|}
\hline Anamorphic form & Teleomorphic form & Synonyms 1 \\
\hline Brettanomyces bruxellensis & Dekkera bruxellensis & \\
\hline Candida colliculosa & Torulaspora delbrueckii & Saccharomyces rosei \\
\hline Candida famata & Debaryomyces hansenii & \\
\hline Candida globosa & Citeromyces matritensis & \\
\hline Candida guilliermondii & Pichia guilliermondii & \\
\hline Candida hellenica & Zygoascus hellenicus & \\
\hline Candida lambica & Pichia fermentans & \\
\hline Candida pelliculosa & Pichia anomala & Hansenula anomala \\
\hline Candida pulcherrima & Metschnikowia pulcherrima & Torulopsis pulcherrima \\
\hline Candida reukaufii & Metschnikowia reukaufii & \\
\hline Candida sorbosa & Issatchenkia occidentalis & \\
\hline Candida stellata & -2 & Torulopsis stellata \\
\hline Candida valida & Pichia membranifaciens & \\
\hline Kloeckera africana & Hanseniaspora vineae & \\
\hline Kloeckera apiculata & Hanseniaspora uvarum & \\
\hline Kloeckera apis & Hanseniaspora guilliermondii & \\
\hline Kloeckera corticis & Hanseniaspora osmophila & \\
\hline Kloeckera javanica & Hanseniaspora occidentalis & \\
\hline-3 & Issatchenkia terricola & Pichia terricola \\
\hline-3 & Kluyveromyces thermotolerans & \\
\hline-3 & Saccharomyces kluyveri & \\
\hline-3 & Saccharomycodes ludwigii & \\
\hline-3 & Zygosaccharomyces bailii & Saccharomyces bailii \\
\hline-3 & Pichia farinosa & \\
\hline
\end{tabular}

${ }^{1}$ Names sometimes found in older literature.

${ }^{2}$ No teleomorphic form.

${ }^{3}$ No anamorphic form.

\section{ECOLOGY OF YEASTS}

Yeasts are found throughout nature. However, they do not occur randomly, but are found in specific habitats where different species form communities (Lachance \& Starmer, 1998). The different species found in a habitat can either be autochothonous (those that are essential components of the community) or allochothonous (those that are transient, or there by chance). The component species within yeast communities are further defined by niches, i.e. the physical, chemical and biotic attributes required by the yeast to survive and grow (Lachance \& Starmer, 1998).

Yeasts found in many different habitats are considered generalists (broad niche), while those found in unique habitats are considered specialists (narrow niche) (Lachance \& Starmer, 1998). Within the winemaking environment (habitat), the vineyard (grape surfaces) and cellar (equipment surfaces and must) can be considered specialised niches where the wine related yeasts can form communities (Polsinelli et al., 1996). These niches differ broadly. The surface of the grape berry before ripeness presents limitations regarding nutrients. These are alleviated as berries ripen and/or are damaged. External factors such as fungicides and pesticides used in the vineyard will have a negative impact on populations. However, it has been reported that some pesticides can stimulate certain yeasts, e.g. K. apiculata, when tested in laboratory fermentations (Cabras et al., 1999).

Grape must is a rich nutritive environment, but low $\mathrm{pH}$ and high osmotic pressure of the must and the use of $\mathrm{SO}_{2}$ detracts from this otherwise ideal yeast niche. Surfaces of cellar equipment can also harbour numerous microorganisms due to constant contact with grape must. Cellar hygiene consequently plays a big role in this niche.

\section{NON-SACCHAROMYCES YEASTS ASSOCIATED WITH GRAPES, FERMENTING MUST AND WINE}

The yeast species found in different niches associated with grape growth (vineyards) and wine production (wineries, grape must, fermentation and wine) can be arbitrarily divided into two groups, i.e. the Saccharomyces group and the non-Saccharomyces group.

The Saccharomyces group with its primary representative, Saccharomyces cerevisiae, is present on grape skins in low numbers (Van Zyl \& Du Plessis, 1961; Rankine, 1972; Török et al., 1996), and on winery equipment and in fermenting must in greater numbers (Peynaud \& Domercq, 1959; Vaughan-Martini \& Martini, 1995). S. cerevisiae is the most important yeast for wine production and is responsible for the metabolism of grape sugar to alcohol and $\mathrm{CO}_{2}$ (Reed \& Peppler, 1973; Fleet, 1993; Pretorius et al., 1999; Pretorius, 2003; Swiegers \& Pretorius, 2005; Swiegers et al., 2005). It has an equally important role to play in the formation of secondary metabolites of importance to wine (Fleet, 1993; Pretorius, 2003), as well as in the conversion of grape aroma precursors to varietal aromas in wine (Darriet et al., 1995; Dubourdieu, 1996; Ribéreau-Gayon et al., 2000; Howell et al., 2004). For these reasons $S$. cerevisiae is often simply referred to as "the wine yeast". The knowledge pertaining to $S$. cerevisiae during wine fermentation can often be applied to nonSaccharomyces yeasts under the same conditions and in the same environment. In addition, as most fields of research are focussed primarily on $S$. cerevisiae, non-Saccharomyces research can be- 
nefit from the techniques developed by the $S$. cerevisiae researchers.

The non-Saccharomyces yeasts contain numerous species, dominated numerically by the apiculate yeasts, e.g. Kloeckera spp. and Candida spp. that are found predominantly on grapes and in freshly processed must. Lesser numbers are found on winery equipment.

The microflora of grapes is affected by a number of factors. These include vineyard altitude and aspect, climatic conditions (temperature, rainfall, humidity, maritime influences), grape variety (cultivar, thickness of grape skin), viticultural practices (fertilisation, irrigation, canopy management, use of fungicides, use of elemental sulphur), developmental stage of grapes, health of grapes (physical damage to berries, insect pests) and winery waste-disposal practices (Bisson \& Kunkee, 1991; Regueiro et al., 1993; Boulton et al., 1996; Epifanio et al., 1999; Pretorius, 2000). The manner in which grapes are sampled (e.g. the berries or bunches) and processed (washing vs. crushing) can also determine what yeasts are isolated (Martini et al., 1980; 1996), as the number of yeast cells is greater close to the peduncle than it is at the centre and lower part of the bunch (Rosini et al., 1982).

At harvest, grape temperature, method of harvest (manual vs. mechanical), method of transport to the cellar (picking crates/baskets, tipsters), time of transport to the cellar, time lapse before crushing, and sulphite and enzyme addition can all affect yeast populations (Pretorius et al., 1999; Pretorius, 2000). Yeasts found on the surface of grapes are introduced into the must at crushing (Bisson \& Kunkee, 1991; Lonvaud-Funel, 1996). Other strains found on the surface of cellar equipment can also be transferred to the must (Boulton et al., 1996). Populations are further affected by the method of crushing, i.e. pressing whole bunches vs. berries, sulphite addition, enzyme addition, cellar hygiene, type of equipment used, clarification method and temperature control (Regueiro et al., 1993; Epifanio et al., 1999; Pretorius et al., 1999; Pretorius, 2000).

The specific environmental conditions in the must, i.e. high osmotic pressure, presence of $\mathrm{SO}_{2}$, and temperature, all play a role in determining what species can survive and grow (Bisson \& Kunkee, 1991; Longo et al., 1991). The fermentation rapidly becomes anaerobic and the alcohol levels increase, which further affects yeast populations.

Despite all the variables in grape harvest and wine production, the yeast species generally found on grapes and in wines are similar throughout the world (Amerine et al., 1967). However, the proportion (or population profile) of yeasts in the different regions shows distinct differences (Amerine et al., 1967; Longo et al., 1991).

In areas with high rainfall during harvest the numbers of nonSaccharomyces yeasts increase (Querol et al., 1990). Pesticides and other chemical sprays used in the vineyard can also affect yeast populations (Monteil et al., 1987; Cabras et al., 1999; Guerra et al., 1999).

The range of non-Saccharomyces species isolated often depends on the place from which, and the stage in the winemaking process at which, the samples are taken (see Tables $3 \& 4$ ). The methods of isolation and enumeration can also impact on the type of yeasts that are isolated, as evident from Table 3. Such methods include shaking grape berries in a broth or crushing whole berries and plating on nutrient agar media. The technique of crushing berries before plating is closer to practical winemaking protocols than is shaking in a broth, but the objective of the investigation will determine which method is chosen.

The type of growth medium used can also play an important role by limiting the growth of specific yeasts. The use of Lysine Medium, for example, does not allow the growth of $S$. cerevisiae due to the inability of this yeast to utilise lysine as the sole carbon source (Fowell, 1965; Heard \& Fleet, 1986). However, some non-Saccharomyces yeasts might also not be able to utilise lysine and, therefore, will not be detected. On a general nutrient agar medium, fast-growing yeasts can also overgrow slow growers. For yeasts with similar growth rates, only yeasts present in the same numerical order will be detected, and more specific techniques and media are needed to isolate slower growing yeasts or yeasts found in low numbers.

The aforementioned limitations can be overcome to a degree by using culture-independent techniques. These include the use of epi-fluorescence microscopy (Du Toit et al., 2005), PCR (polymerase chain reaction) based DGGE (denaturing gradient gel electrophoreses) (Cocolin et al., 2000; Prakitchaiwattana et al., 2004) and FT-IR (Fourier-transform infrared) spectroscopy (Wenning et al., 2002).

\section{Non-Saccharomyces yeasts in vineyards and on grapes}

Low numbers of yeasts $\left(10-10^{3} \mathrm{cfu} / \mathrm{g}\right)$ are found on unripe grapes, but as the grapes ripen the numbers increase to $10^{4}-10^{6} \mathrm{cfu} / \mathrm{g}$ (Fleet, 2003). This is due to sugars that leach or diffuse out from inner tissue to the grape skin surfaces, providing nutrition for the yeasts. Damaged berries increase the leaching effect. Therefore, the maturity of the grapes and/or the degree of damage to grape berries will largely determine the population numbers.

Generally, between nine and 15 culturable yeast species are found on grapes (Du Plessis, 1959; Van Zyl \& Du Plessis, 1961; Parish \& Caroll, 1985; Yanagida et al., 1992; Regueiro et al., 1993; Zahavi et al., 2002; Jolly et al., 2003a; Rementeria et al., 2003). These include Hanseniaspora/Kloeckera spp., Metschnikowia/Candida spp., Rhodotorula spp. and Cryptococcus spp. Unfortunately, comparisons between different studies are difficult, as different approaches have been used for grape sampling and yeast isolation (see Table 3). In addition, the state of ripeness and berry damage is never given. Further factors that can influence a yeast population include specific meso- and microclimates in vineyards. Notwithstanding, there is general agreement that the most frequently occurring species in vineyards are usually the apiculate yeasts, $K$. apiculata/Hanseniaspora uvarum (50-75\% of isolates) (Van Zyl \& Du Plessis, 1961; Yanagida et al., 1992; and a recent review by Pretorius, 2000). It has been reported that in warm to hot regions the teleomorphic form (H. uvarum) tends to replace the anamorphic form (K. apiculata), while the anamorphic form is present in greater numbers in cooler regions (Bisson \& Kunkee, 1991; Jackson, 1994; Boulton et al., 1996). In moderate climates both types occur in equal numbers. However, this distribution between the teleomorphic and anamorphic forms might be region dependent. Altitude also appears to play a role as it has been reported that Kloeckera spp. are found more frequently at high altitudes and Hansenia- 
spora spp. more frequently at low altitudes. This might be linked to temperature. Identification of Kloeckera vs. Hanseniaspora yeasts also depends on how long the yeasts have been conserved before identification (Yarrow, 1998; M. Th. Smith, personal communication, 2000).

According to Van Zyl \& Du Plessis (1961), the following yeasts occurred in highest frequency in South African vineyards: K. apiculata, Rhodotorula glutinis, Candida krusei, Candida pulcherrima, Candida laurentii, Cryptococcus albidus, and Candida stellata (T. bacillaris). In a more recent, but limited, investigation (Jolly et al., 2003a), K. apiculata, C. pulcherrima and a Rhodotorula sp. were still found in dominant numbers but Kluyveromyces thermotolerans and Zygosaccharomyces bailii were also isolated. Studies by Le Roux et al. (1973) showed that Botrytis cinerea infection of grapes influenced the non-Saccharomyces populations - C. krusei and K. apiculata increased and $R$. glutinis decreased. Other non-Saccharomyces yeasts found on grapes and in vineyards are shown in Table 3.

\section{Non-Saccharomyces yeasts associated with fermenting must}

During crushing, the non-Saccharomyces yeasts on the grapes, on cellar equipment and in the cellar environment (air- and insectborne) are carried to the must (Peynaud \& Domercq, 1959; Bisson \& Kunkee, 1991; Boulton et al., 1996; Lonvaud-Funel, 1996; Török et al., 1996; Constantí et al., 1997; Mortimer \& Polsinelli, 1999; Fleet, 2003). Non-Saccharomyces species that have been isolated from cellar surfaces include Pichia anomala, Pichia membranifaciens, Candida spp., Cryptococcus spp. and, more rarely, Rhodotorula spp., Debaryomyces hansenii, K. apiculata and Metschnikowia pulcherrima (Loureiro \& MalfeitoFerreira, 2003). However, cellar surfaces play a smaller role than grapes as a source of non-Saccharomyces yeasts, as $S$. cerevisiae is the predominant yeast inhabiting such surfaces (Peynaud \& Domercq, 1959; Rosini, 1984; Lonvaud-Funel, 1996; Pretorius, 2000). Furthermore, hygienic procedures used in most modern cellars should minimise contamination of must by resident cellar flora (Jackson, 1994; Pretorius, 2000). It might therefore be expected that the dominant yeasts in must after crushing will be the same as are found on grapes (Rementeria et al., 2003).

The specific environmental conditions in grape must are limiting and hostile to yeasts due to low $\mathrm{pH}$, high sugar (high osmotic pressure), an equimolar mixture of glucose and fructose, presence of $\mathrm{SO}_{2}$ and a non-optimal growth temperature during cold settling (Bisson \& Kunkee, 1991; Longo et al., 1991; Pretorius, 2000). Furthermore, the environment rapidly becomes anaerobic, with increasing levels of ethanol that is toxic to yeasts. Nitrogen levels are usually sufficient at the start of fermentation (Bisson \& Kunkee, 1991), but can be limiting towards the end of fermentation unless supplemented. The clarification of white must (centrifugation, enzyme treatments, cold settling) can also reduce the initial population of yeasts (Fleet, 1990; Lonvaud-Funel, 1996; Pretorius, 2000).

Non-Saccharomyces yeasts found in grape must and during fermentation (see Table 4) can be divided into three groups:

(i) yeasts that are largely aerobic, e.g. Pichia spp., Debaryomyces sp., Rhodotorula spp., Candida spp. (e.g. C. pulcherrima and C. stellata), and Cryptococcus albidus;

(ii) apiculate yeasts with low fermentative activity, e.g.

\section{K. apiculata (H. uvarum), Kloeckera apis, Kloeckera javanica; and}

(iii) yeasts with fermentative metabolism, e.g. Kluyveromyces marxianus, Torulaspora spp. (e.g. T. globosa and T. delbrueckii) and Zygosaccharomyces spp. (Fleet et al., 1984; Querol et al., 1990; Bisson \& Kunkee, 1991; Longo et al., 1991; Lonvaud-Funel, 1996; Lorenzini, 1999; Torija et al., 2001; Combina et al., 2005).

During fermentation, and especially in spontaneous fermentations, there is a sequential succession of yeasts. Initially, species of Kloeckera (Hanseniaspora), Rhodotorula, Pichia, Candida (C. stellata, C. pulcherrima [M. pulcherrima], Candida sake) and Cryptococcus are found at low levels in the fresh must (Parish \& Caroll, 1985; Bisson \& Kunkee, 1991; Frezier \& Dubourdieu, 1992; Jackson, 1994; Granchi et al., 1998; Fleet, 2003; Combina et al., 2005). Of these, K. apiculata is usually present in the highest numbers, followed by various Candida spp.

In a study of South African musts, however, very few K. apiculata yeasts were found (Van Zyl \& Du Plessis, 1961). This was attributed to the addition of large quantities of $\mathrm{SO}_{2}$ to the must to aid settling. In another study on muscadine (Vitis rotundifolia) grapes from North Carolina H. uvarum (K. apiculata) was absent, but Hanseniaspora osmophilia and P. membranifaciens predominated during the initial stages of the fermentation (Parish \& Caroll, 1985). This might be an association for that particular geographic area or grape type. However, viticultural practices could have affected the normal non-Saccharomyces population. At the start of fermentation an initial proliferation of apiculate yeasts (Kloeckera and Hanseniaspora) normally occurs. This is usually more apparent in red must than in white, possibly due to the higher $\mathrm{pH}$ of the former.

In the past it was generally believed that all non-Saccharomyces yeasts died soon after the commencement of an alcoholic fermentation due to the increasing ethanol concentration and added $\mathrm{SO}_{2}$. However, more recent work has shown that some non-Saccharomyces yeasts can survive to a later stage of fermentation (up to 12 days) than initially believed (Fleet et al., 1984; Heard \& Fleet, 1985; Fleet, 1990; Longo et al., 1991; Todd, 1995; Gafner et al., 1996; Granchi et al., 1998; Zohre \& Erten, 2002; Fleet, 2003; Combina et al., 2005). Other non-Saccharomyces yeasts might be present throughout the fermentation, reaching cell densities of $10^{6}$ to $10^{8}$ cells $/ \mathrm{mL}$ (Fleet et al., 1984; Combina et al., 2005). This sustained growth of non-Saccharomyces spp. is more evident in spontaneous fermentations, which lack the initial high density inoculum of $S$. cerevisiae. Abnormal vintages due, for example, to excessive rainfall during grape ripening, also contribute to greater numbers of non-Saccharomyces yeasts in the initial stages and later in the fermentation (Querol et al., 1990). Non-Saccharomyces yeasts have also been observed to grow to levels of $c a$. $10^{4}$ cells $/ \mathrm{mL}$ in red wines during malo-lactic fermentations (Fleet et al., 1984).

Despite the sustained presence of certain non-Saccharomyces yeasts, the majority disappear during the early stages of a vigorous fermentation (Fleet et al., 1984; Jackson, 1994; Henick-Kling et al., 1998). This might be due to their slow growth and inhibition by the combined effects of $\mathrm{SO}_{2}$, low $\mathrm{pH}$, high ethanol content and oxygen deficiency (Jackson, 1994; Combina et al., 2005). 


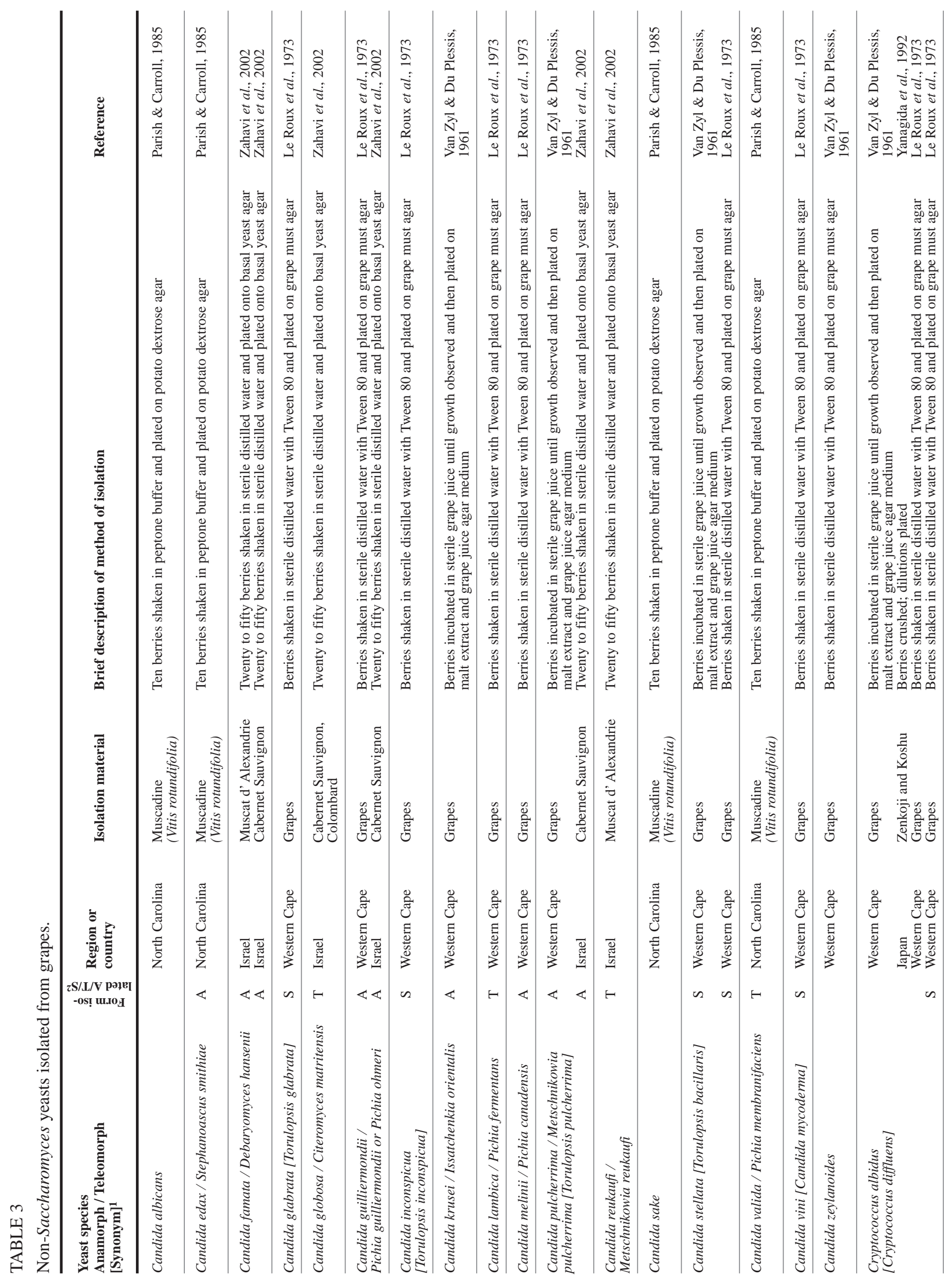




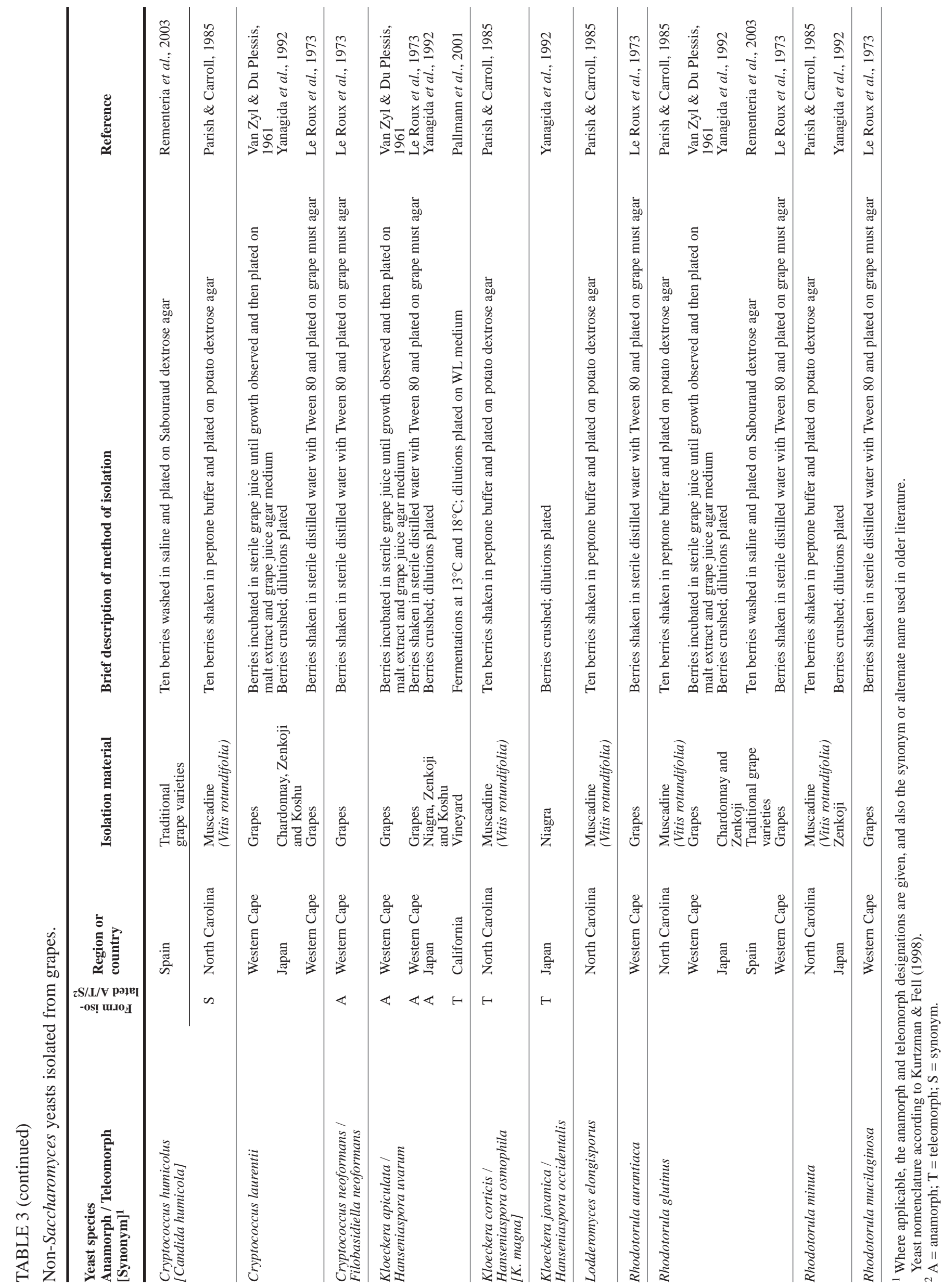


This is consistent with their oxidative or weak fermentative metabolism. Nutrient limitation and size of $S$. cerevisiae inoculum would also have a suppressive effect. Granchi et al. (1998) reported that numbers of $K$. apiculata declined once $S$. cerevisiae became dominant rather than when the fermentation temperature and ethanol concentration reached values known to inhibit apiculate yeast growth. It has also been reported that $T$. delbrueckii and $K$. thermotolerans are less tolerant to low oxygen levels and it is this, rather than ethanol toxicity, that affects their growth and leads to their death during fermentation (Hansen et al., 2001). It was also shown that a cell-cell contact mechanism in the presence of high concentrations of viable $S$. cerevisiae yeasts played a role in the inhibition of these two non-Saccharomyces species (Nissen et al., 2003).

The non-Saccharomyces spp. that survive and are present until the end of fermentation may also have a higher tolerance to ethanol. It has been documented that $C$. stellata (Torulopsis stellata) can tolerate up to $12 \%$ ethanol (Combina et al., 2005), which would account for its sustained presence during fermentation. Other species reported throughout fermentation are Z. bailii (Saccharomyces acidifaciens) (Peynaud \& Domercq, 1959) and Pichia sp. (Bisson \& Kunkee, 1991).

The extent to which different factors affect the nonSaccharomyces yeasts are dependent on the characteristics of the individual species. Growth parameters for one species will not necessarily be the same for others. Variations can also occur for strains within a species.

\section{Non-Saccharomyces yeasts associated with wine}

Non-Saccharomyces yeasts in wine are usually associated with wines in barrels and post-fermentation spoilage (Van der Walt \& Van Kerken, 1958; Amerine \& Cruess, 1960; Van Zyl, 1962; Heresztyn, 1986; Grbin, 1999; and a recent review by Loureiro \& Malfeito-Ferreira, 2003). However, only a small number are able to tolerate the adverse conditions in wine, and multiply (Van Kerken, 1963). These include Brettanomyces spp. (Dekkera spp.), Z. bailii, P. membranifaciens, C. krusei and C. valida (Van Kerken, 1963; Fleet et al., 1984; Parish \& Caroll, 1985; Bisson \& Kunkee, 1991; Grbin, 1999). Some of these species, e.g. Brettanomyces spp. and Zygosaccharomyces spp. are as ethanol tolerant as $S$. cerevisiae and may be found in bottled wine. Their presence is influenced by the degree of filtration that precedes bottling and cellar hygiene during bottling.

\section{THE ROLE OF NON-SACCHAROMYCES YEASTS IN WINE PRODUCTION}

The role of non-Saccharomyces yeasts in wine production has been debated extensively (Castor, 1954; Van Zyl et al., 1963; Fleet et al., 1984; Heard \& Fleet, 1985; Fleet, 1990; Herraiz et al., 1990; Longo et al., 1991; Romano et al., 1992; Todd, 1995; Gafner et al., 1996; Gil et al., 1996; Lema et al., 1996; Granchi et al., 1998; Henick-Kling et al., 1998; Lambrechts \& Pretorius, 2000; Fleet, 2003; Rementeria et al., 2003; Combina et al., 2005). As already discussed, grape musts contain a mixture of yeast species. Wine fermentation is therefore not a single-species fermentation (Fleet, 1990), although the dominance of $S$. cerevisiae (inoculated or indigenous) in the fermentation is expected and desired. However, the indigenous non-Saccharomyces yeasts, already present in the must, and often in greater numbers than
S. cerevisiae, are adapted to the specific environment and are in an active growth state, giving them a competitive edge.

Despite a long-held belief among winemakers in Old World wine regions that spontaneous fermentations (comprising mixed cultures of non-Saccharomyces and Saccharomyces yeasts) produce superior wines compared with pure culture fermentations, earlier authors usually refer to the non-Saccharomyces yeasts as spoilage organisms or 'wild yeasts' (Amerine \& Cruess, 1960; Van Zyl \& Du Plessis, 1961; Van Kerken, 1963; Rankine, 1972; Le Roux et al., 1973). This was substantiated by their frequent isolation from stuck fermentations and from spoiled bottles of wine.

Furthermore, although it was known that some nonSaccharomyces yeasts could form metabolites, e.g. esters, leading to aromas not always detrimental to wine quality (Castor, 1954; Amerine \& Cruess, 1960; Van Zyl et al., 1963), this was outweighed by the high levels of volatile acids and other undesirable compounds produced (Castor, 1954; Amerine \& Cruess, 1960; Van Zyl et al., 1963; Amerine et al., 1967; 1972). Some yeasts, e.g. Candida, Pichia and Hansenula spp. are capable of forming films on the surface of wine exposed to oxygen. Off-odours, including acetic acid, ethyl acetate and acetaldehyde are also associated with their growth (Grbin, 1999). Brettanomyces spp. (Dekkera spp.) can contribute to 'animal/farmyard/mousy' taints in wines (Parish \& Caroll, 1985; Grbin, 1999, Grbin \& Henschke, 2000; Arvik \& Henick-Kling, 2002; Du Toit et al., 2005). It has also been reported that Brettanomyces bruxellensis can form biogenic amines (Caruso et al., 2002) that can lead to undesirable physiological effects in sensitive humans. Other nonSaccharomyces yeasts such as Saccharomycodes ludwigii, more commonly a contaminant of sulphated musts due to its high resistance to $\mathrm{SO}_{2}$, produce large amounts of ethyl acetate and acetaldehyde that negatively affect wine aroma and quality (Ciani \& Maccarelli, 1998).

Authors of earlier publications also considered nonSaccharomyces yeasts to be sensitive to $\mathrm{SO}_{2}$ in must and added $\mathrm{SO}_{2}$ primarily to control their growth and that of spoilage bacteria (Amerine \& Cruess, 1960; Van Zyl \& Du Plessis, 1961; Amerine et al., 1972). Non-Saccharomyces yeasts were also known to be poor fermenters of grape must and intolerant to ethanol (Castor, 1954), especially in the presence of $\mathrm{SO}_{2}$ (Amerine et al., 1972). It was therefore accepted that those nonSaccharomyces yeasts not initially inhibited by the $\mathrm{SO}_{2}$ died during fermentation due to the combined toxicity of the $\mathrm{SO}_{2}$ and alcohol. Consequently, the non-Saccharomyces yeasts were seen to be of little significance in normal wine production and it was recommended that only proven strains of the wine yeast $S$. cerevisiae be used in commercial fermentations (Amerine \& Cruess, 1960; Amerine et al., 1972).

As already mentioned, non-Saccharomyces yeasts can survive and reach high cell densities, similar to $S$. cerevisiae $\left(10^{6}\right.$ to $10^{8}$ cells/mL), during fermentation. More recently reported higher numbers of non-Saccharomyces yeasts might be the result of improved cellar technology and hygiene in modern cellars that has led to a reduction in $\mathrm{SO}_{2}$ usage, presumably resulting in the survival of a greater number and diversity of non-Saccharomyces yeasts. Coupled to this is the use of modern laboratory techniques that makes the detection of non-Saccharomyces yeasts easier. 


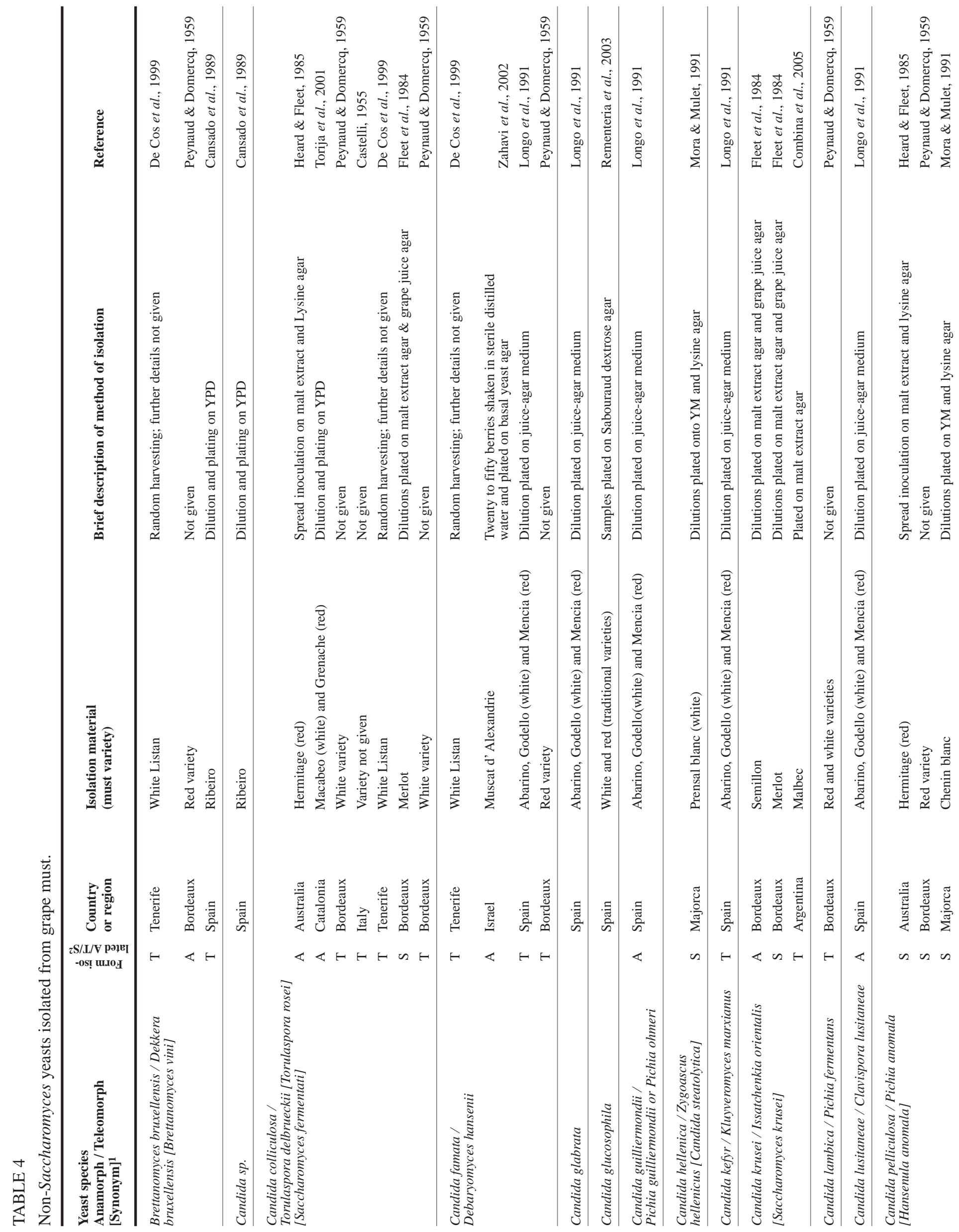




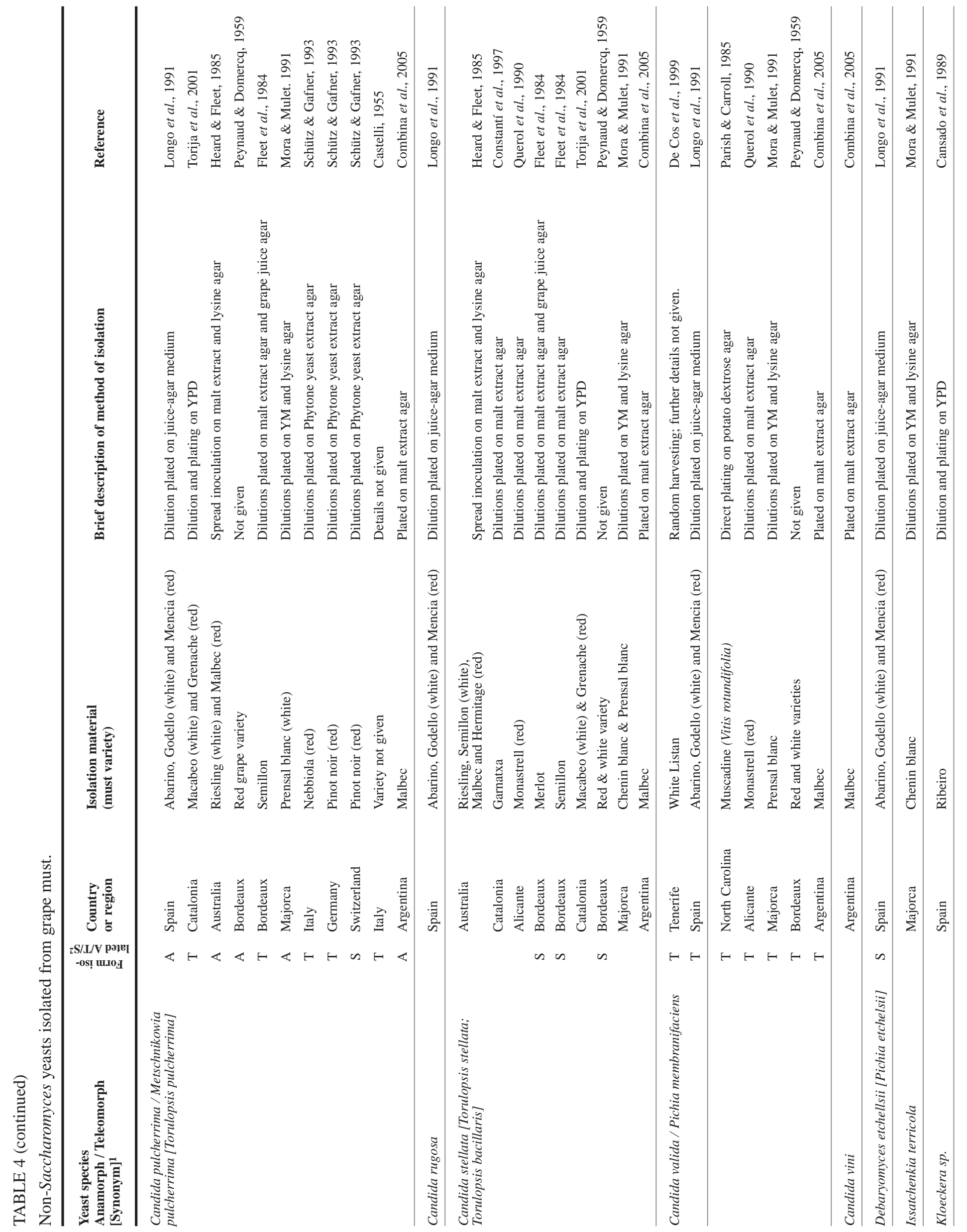




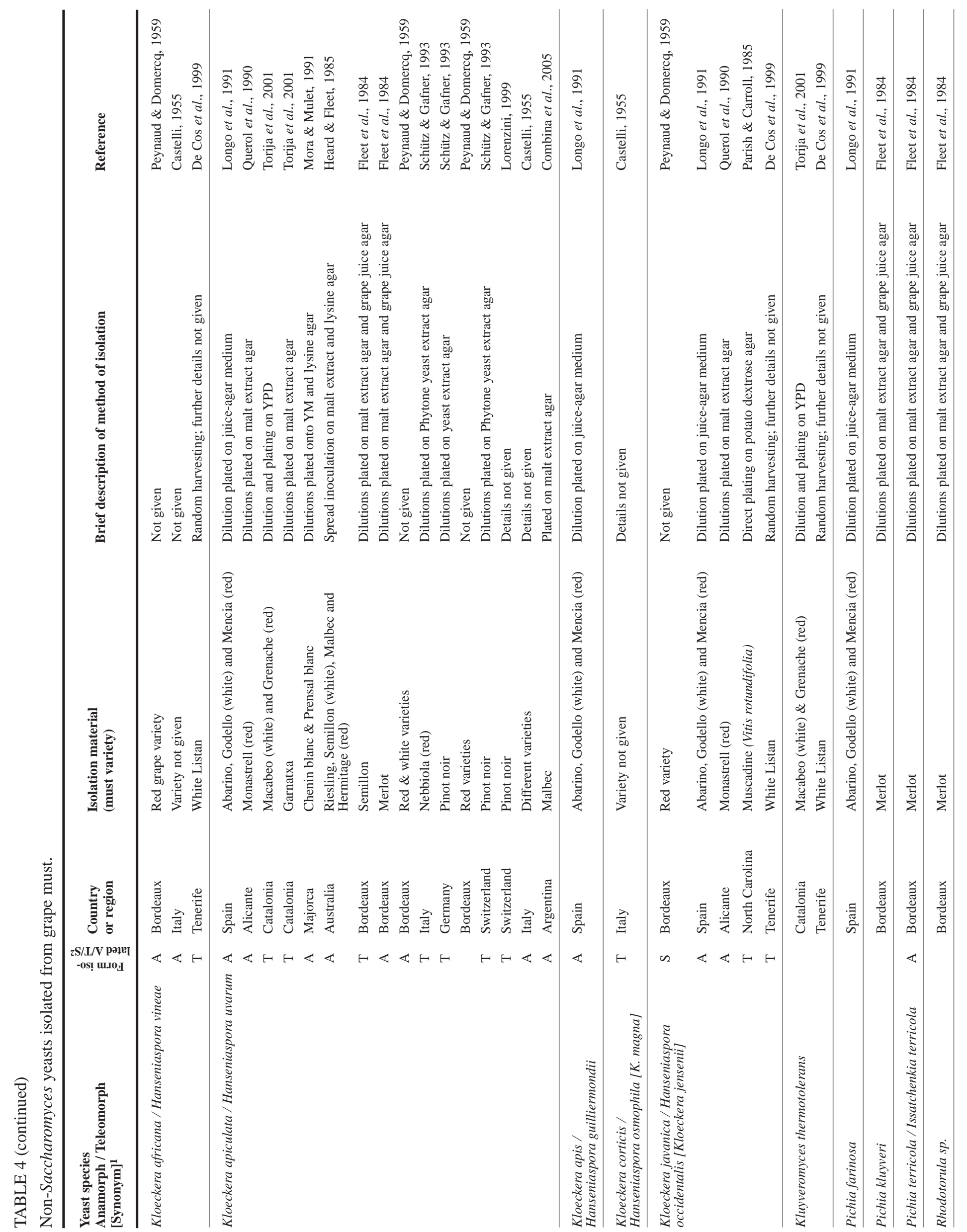




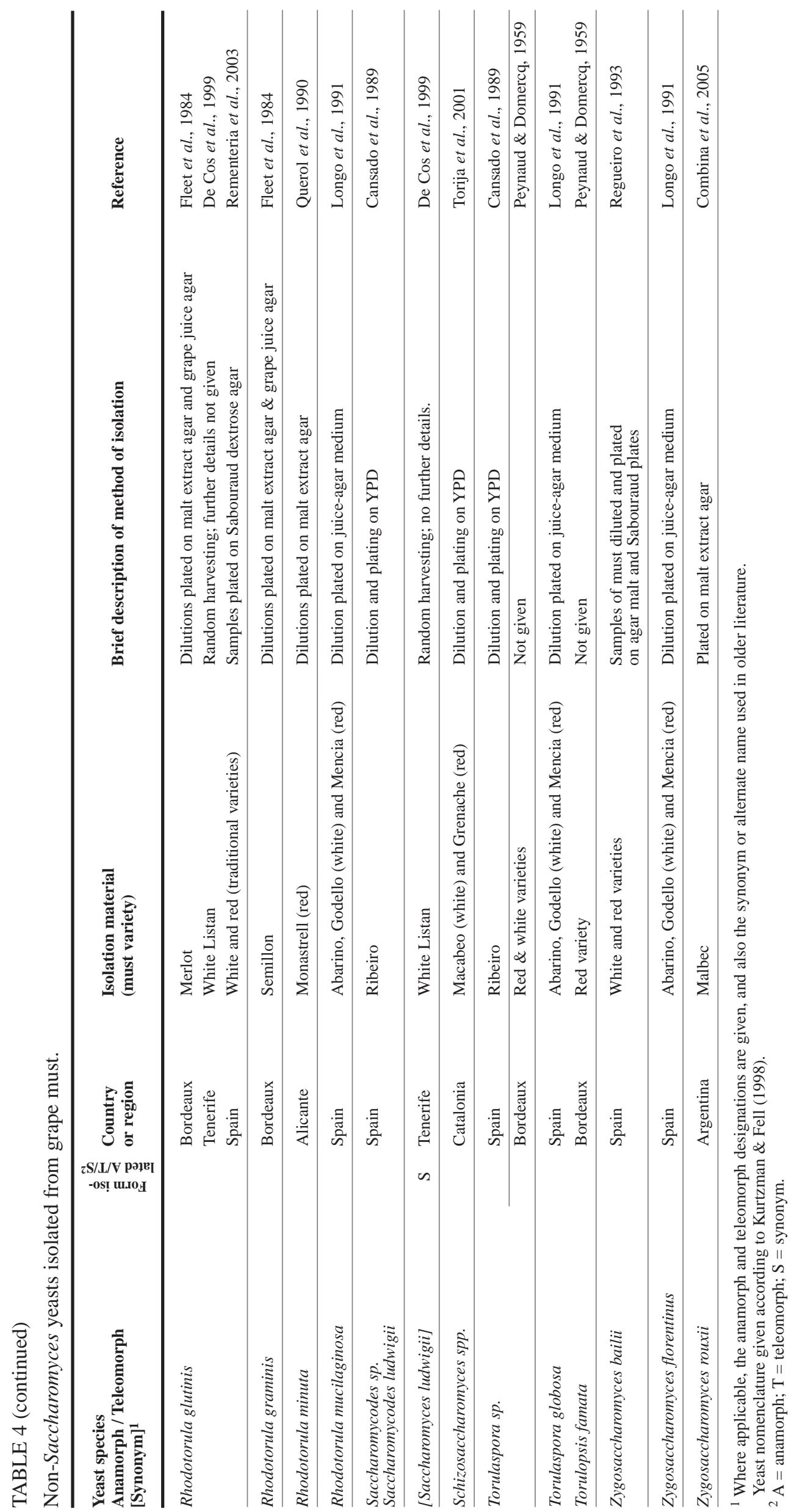


The high numbers and sustained presence of nonSaccharomyces yeasts in modern wine fermentations have resulted in wine microbiologists revisiting the role of these yeasts in wine fermentation. Spontaneously fermented wines, although carrying a higher risk of spoilage, are generally regarded as having improved complexity, mouth-feel (texture) and integration of flavours relative to inoculated wines (Heard \& Fleet, 1985; Bisson \& Kunkee, 1991; Gil et al., 1996; Lema et al., 1996; Grbin, 1999; Soden et al., 2000). This is due to specific metabolic end products.

Documented cases include the study by Lema et al. (1996) on Albariño wine aroma components. These authors concluded that the predominance of inoculated $S$. cerevisiae, along with a notable growth rate of indigenous non-Saccharomyces yeasts during the first days of the wine fermentation, contributed significantly to the desirable aromatic properties of the wines. Herraiz et al. (1990) and Gil et al. (1996) also reported that wines produced by pure and mixed cultures of $S$. cerevisiae and apiculate yeasts ( $K$. apiculata and $H$. uvarum) differ regarding their aromatic compounds. The low frequency of Kloeckera spp. during fermentation has also been suggested as a reason for the lack of aroma complexity of Folle blanche wines in the Basque region in Spain (Rementeria et al., 2003).

The range of flavour compounds produced by different yeasts is well documented (Castor, 1954; Suomalainen \& Lehtonen, 1979; Soles et al., 1982; Nykänen, 1986; Rauhut, 1993; Romano \& Suzzi, 1993a; Lambrechts \& Pretorius, 2000; Rojas et al., 2003; Romano et al., 2003; Moreira et al., 2005; Swiegers \& Pretorius, 2005; Swiegers et al., 2005). The metabolic products resulting from non-Saccharomyces growth include glycerol, acetaldehyde, acetic acid, succinic acid, higher alcohols and fatty acid esters (Fleet et al., 1984; Bisson \& Kunkee, 1991; Jackson, 1994; Boulton et al., 1996; Lonvaud-Funel, 1996; Heard, 1999; Zohre \& Erten, 2002; Clemente-Jimenez et al., 2004).

Glycerol, after ethanol, is the next major yeast metabolite produced during wine fermentation and is important in yeast metabolism for regulating the redox potential in the cell (Scanes et al., 1998; Prior et al., 2000). Glycerol contributes to smoothness (mouth-feel), sweetness and complexity in wines (Ciani \& Maccarelli, 1998), but the grape variety and wine style will determine the extent to which glycerol impacts on these properties. It appears that the quality of Chardonnay, Sauvignon blanc and Chenin blanc is not improved by increased glycerol concentrations (Nieuwoudt et al., 2002). However, as all wine sensory profiles are unique, some wines might benefit from increased glycerol levels.

Spontaneously fermented wines have higher glycerol levels, indicating a possible contribution by non-Saccharomyces yeasts (Romano et al., 1997; Henick-Kling et al., 1998). It is known that C. stellata produces elevated glycerol concentrations of between 10 and 14 g/L (Ciani \& Picciotti, 1995; Ciani \& Ferraro, 1998), compared with 4 to $10.4 \mathrm{~g} / \mathrm{L}$ by S. cerevisiae (Radler \& Schütz, 1982; Ciani \& Maccarelli, 1998; Prior et al., 2000). Unfortunately, increased glycerol production is usually linked to increased acetic acid production (Prior et al., 2000), which can be detrimental to wine quality. This makes the growth of $C$. stellata during fermentation problematic, unless a balance can be achieved between glycerol and acetic acid production, which will not detract from wine quality.
Apiculate yeasts ( $K$. apiculata and Hanseniaspora guilliermondii) have also been implicated in glycerol production. These yeasts can generally be divided into two groups, i.e. high-glycerol (3 g/L), low ethanol $(0.9 \% \mathrm{v} / \mathrm{v})$ producers, and low- glycerol (1 g/L), high-ethanol $(2.4 \% \mathrm{v} / \mathrm{v})$ producers (Romano et al., 1997). Apiculate yeasts are also known as high producers of acetic acid, making them undesirable for wine production (Ciani \& Picciotti, 1995). However, it has been reported that large strain variability exists and that not all strains of Kloeckera spp. form high levels of acetic acid (Romano et al., 1992). Some strains form less than $1 \mathrm{~g} / \mathrm{L}$ and are comparable to $S$. cerevisiae. If these strains also form higher levels of glycerol, their use can benefit a wine for which higher glycerol levels are needed.

The primary flavour of wine is derived from the grapes. However, secondary flavours are derived from ester formation by yeasts during wine fermentation (Nykänen, 1986; Lambrechts \& Pretorius, 2000). Over 160 esters have been distinguished in wine (Jackson, 2000). These esters can have a positive effect on wine quality, especially in wine from varieties with neutral flavours that are consumed shortly after production, e.g. some Chenin blanc wines (Lambrechts \& Pretorius, 2000). Non-Saccharomyces yeasts isolated from South African musts during 1961 could be divided into two groups, viz. neutral yeasts (producing little or no flavour compounds) and flavour producing species (both desired and undesired) (Van Zyl et al., 1963). Flavour producing yeasts included $P$. anomala (Hansenula anomala) and K. apiculata. C. pulcherrima is also known to be a high producer of esters (Bisson \& Kunkee, 1991; Clemente-Jimenez et al., 2004). However, C. pulcherrima has an antagonistic effect on several yeasts, including S. cerevisiae (Panon, 1997; Nguyen \& Panon, 1998). When aerobic growth of $C$. pulcherrima cultures was followed by inoculation with $S$. cerevisiae, delays in fermentation occurred. This was due to a killer effect, but it was not the same as the classical $S$. cerevisiae killer phenomenon; it was linked to pulcherrimin pigment produced by $C$. pulcherrima. Contrary reports (Jolly et al., 2003b, 2003c) indicate that when using a $C$. pulcherrima isolate for wine production there was no effect on fermentation. This contradiction might be due to different distinct biotypes within the C. pulcherrima species (Pallmann et al., 2001), but this still needs to be investigated further.

Other yeasts that can play a role in wine production are those of the genus Brettanomyces (Dekkera). Different Brettanomyces strains can develop flavours ranging from pleasantly fruity and toffee, to volatile and unpleasant (Eschenbruch \& Wong, 1993). The 'mousy' and 'medicinal-like' character in wine (known as "Brett"), is linked to the growth of Brettanomyces spp. and is due to the formation of tetrahydropyridines and 4-ethyl phenol, respectively (Grbin et al., 1995; Grbin \& Henschke, 2000; Arvik \& Henick-Kling, 2002). This 'Brett' character is considered to be an off-flavour. However, anecdotal evidence indicates that the 'Brett' character, at low levels in a red wine with an overall complex aroma, can be a positive addition.

Some non-Saccharomyces yeasts, e.g. T. delbrueckii and C. stellata are able to form succinic acid (Ciani \& Maccarelli, 1998; Ferraro et al., 2000). This correlates with high ethanol production and ethanol tolerance. Succinic acid production could positively influence the analytical profile of wines by contributing to the total acidity in wines with insufficient acidity. However, 
succinic acid has a salty/bitter-acid taste (Amerine at al., 1972) and excessive levels will negatively influence wine quality.

Different non-Saccharomyces yeasts produce different levels of higher alcohols (n-propanol, isobutanol, isoamyl alcohol, active amyl alcohol) (Romano et al., 1992; Lambrechts \& Pretorius, 2000). This is important during wine production, as high concentrations of higher alcohols are generally not desired, but lower values can add to wine complexity (Romano \& Suzzi, 1993b). Non-Saccharomyces yeasts often form lower levels of these alcohols than $S$. cerevisiae, but there is great strain variability (Romano et al., 1992, 1993; Zironi et al., 1993).

Other non-Saccharomyces metabolites can act as intermediates in aroma metabolic pathways. Romano et al. (1993) showed that $H$. guilliermondii and $K$. apiculata strains produced 50.3 to 258.1 $\mathrm{mg} / \mathrm{L}$ and 55.8 to $187.4 \mathrm{mg} / \mathrm{L}$ acetoin, respectively, in grape must. Acetoin is considered a relatively odourless compound in wine, with a threshold value of approximately $150 \mathrm{mg} / \mathrm{L}$ (Romano \& Suzzi, 1996). However, diacetyl and 2,3-butanediol (potentially off-flavours in wine) can be derived from acetoin by chemical oxidation and yeast-mediated reduction, respectively. This indicates that acetoin can play a role in off-flavour formation in wines. High concentrations of acetoin produced by nonSaccharomyces yeasts can also be utilised by $S$. cerevisiae. This was shown by Zironi et al. (1993) in their chemical analysis results of wines fermented from pure cultures, compared to mixed and sequential culture fermentations. They could not, however, confirm what metabolites were formed from acetoin by S. cerevisiae.

These, and other compounds not discussed in this article (e.g. volatile fatty acids, carbonyl and sulphur compounds), are known to play a role in the sensory quality of wine (Nykänen, 1986; Lambrechts \& Pretorius, 2000; Moreira et al., 2005). However, as stated by Guth (1997), there are over 680 documented compounds in wine and a large number of these can, depending on their concentrations, contribute either positively or negatively to wine aroma and flavour. It is not known how these compounds relate to the metabolism of the different yeast species found in fermentation.

Certain flavour and aroma compounds are present in grapes as glycosidic precursors with no sensory properties (Todd, 1995; Pretorius, 2003). These compounds may be hydrolysed by the enzyme $\beta$-glucosidase to form free volatiles that can improve the flavour and aroma of wine, but this enzyme is not encoded by the S. cerevisiae genome (Ubeda-Iranzo et al., 1998; Van Rensburg et al., 2005). However, certain non-Saccharomyces yeasts belonging to the genera Debaryomyces, Hansenula, Candida, Pichia and Kloeckera possess various degrees of $\beta$-glucosidase activity (Rosi et al., 1994; Todd, 1995; Spagna et al., 2002; FernándezGonzáles et al., 2003; Rodriguez et al., 2004) and can play a role in releasing volatile compounds from non-volatile precursors. An intracellular $\beta$-glucosidase has also been isolated and purified from Debaryomyces hansenii. This enzyme, which is not inhibited by glucose and ethanol, was used during fermentation of Muscat grape juice, resulting in an increase in concentration of monoterpenols in the wine (Yanai \& Sato, 1999).

As already mentioned, ester formation by yeast plays an important role in secondary flavours. However, the net accumulation of esters in wine is determined by the balance between the yeast's ester-synthesising enzymes and esterases (responsible for cleavage and, in some cases, formation of ester bonds) (Swiegers \& Pretorius, 2005). Although extracellular esterases are known to occur in S. cerevisiae (Ubeda-Iranzo et al., 1998), the situation for non-Saccharomyces needs further investigation.

Other non-Saccharomyces extracellular enzymatic activity (e.g. proteolytic, polygalacturonase) might also be of use in winemaking. For example, proteolytic activity of some non-Saccharomyces yeasts could lead to a reduction in protein levels, with an accompanying increase in protein stability. However, Dizy \& Bisson (2000) reported to the contrary, namely that increased yeast proteolytic activity did not lead to a reduction in haze formation. Some extracellular enzymes produced by non-Saccharomyces species are shown in Table 5. Species found to produce the greatest number of extracellular enzymes are C. stellata, H. uvarum/K. apiculata and M. pulcherrima/C. pulcherrima.

New research by Carrau et al. (2005) on the formation of aroma compounds by yeasts suggests that $S$. cerevisiae can synthesise monoterpenes (floral aroma in wine), compounds previously thought to be solely derived from grapes. They have also proposed a new metabolic pathway (MCC pathway). It is unknown whether any non-Saccharomyces yeasts have these capabilities. However, considering the large variety of non-Saccharomyces yeast species found in grape must, it is likely that there will be some.

\section{FACTORS AFFECTING GROWTH OF NON-SACCHARO- MYCES YEASTS DURING WINE FERMENTATION}

The contribution by non-Saccharomyces yeasts to wine flavour will depend on the concentration of metabolites formed. Therefore, any factors affecting the growth rate of individual nonSaccharomyces species will determine the extent of their contribution to flavour development (Heard, 1999). These factors include intrinsic components of grape juice ( $\mathrm{pH}$, sugar concentration and clarity), processing methods (method of clarification, use of preservatives and/or $\mathrm{SO}_{2}$ ), fermentation conditions (temperature, oxygen content/aeration) and the effect of $S$. cerevisiae yeast, e.g. amount of ethanol formed.

Non-Saccharomyces yeasts have poor tolerance to low oxygen availability, especially compared with $S$. cerevisiae (Hansen et $a l ., 2001)$. The removal of oxygen by vigorously fermenting $S$. cerevisiae can contribute to an early death of some nonSaccharomyces yeasts.

For some non-Saccharomyces yeasts, i.e. C. stellata, C. colliculosa and $C$. pulcherrima, it has been shown that the $\mathrm{pH}$ of the medium or must does not have a large effect on growth rate (Gao \& Fleet, 1988; Heard \& Fleet, 1988), however, it has also been reported that higher $\mathrm{pH}$ increases the fermentation ability of C. pulcherrima (Jolly et al., 2003c). The effect of $\mathrm{pH}$ on other non-Saccharomyces yeasts is not well defined. An increase in sugar concentration, however, does have an effect on nonSaccharomyces yeasts due to their generally poor osmotolerance (Heard, 1999).

Temperature and $\mathrm{SO}_{2}$ are possibly the two factors that have the greatest effect on non-Saccharomyces yeasts. Some nonSaccharomyces yeasts are inhibited at temperatures above $25^{\circ} \mathrm{C}$ (Sharf \& Margalith, 1983; Fleet, 1990; Boulton et al., 1996). 
TABLE 5

Extracellular hydrolytic enzymes found in non-Saccharomyces yeasts.

Extracellular enzyme activity

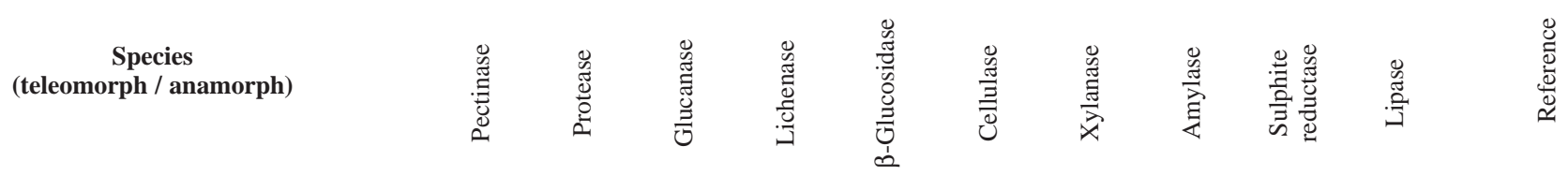

Zygoascus hellenicus / Candida hellenica

Brettanomyces clausenii

Kluyveromyces thermotolerans

Pichia fermentans / Candida lambica

-2 / Candida oleophila

Issatchenkia occidentalis / Candida sorbosa

-2 / Candida stellata

Pichia membranifaciens / Candida valida

Debaryomyces hansenii / Candida famata

Hanseniaspora uvarum / Kloeckera apiculata

Issatchenkia orientalis / Candida krusei

Metschnikowia pulcherrima / Candida pulcherrima

Pichia anomala / Candida pelliculosa

Torulaspora delbrueckii / Candida colliculosa

Pichia farinosa $/^{-3}$

Debaryomyces castellii / ${ }^{-3}$

Debaryomyces polymorphus $/^{-3}$

Pichia kluyveri / ${ }^{-3}$

Pichia guilliermondii / Candida guilliermondii

\begin{tabular}{|c|c|c|c|c|c|c|c|c|}
\hline \multirow[t]{3}{*}{+} & & + & & & & + & & $\bar{S}$ \\
\hline & & & & & & & & $\mathrm{F}$ \\
\hline & & & & & & & & $\mathrm{F}$ \\
\hline \multirow[t]{2}{*}{+} & & & & & & + & & S \\
\hline & & & & + & & + & & $\mathrm{S}$ \\
\hline+ & & & & & & + & & $\mathrm{S}$ \\
\hline \multirow[t]{3}{*}{+} & + & & + & + & + & + & + & $\mathrm{C}, \mathrm{F}, \mathrm{S}$ \\
\hline & & + & & & & + & & $\mathrm{F}, \mathrm{S}$ \\
\hline & & + & & & & + & & $\mathrm{R}^{4}, \mathrm{~S}, \mathrm{~B}$ \\
\hline \multirow[t]{2}{*}{+} & + & + & + & + & + & + & & $\mathrm{R}^{4}, \mathrm{C}, \mathrm{S}, \mathrm{Ro}^{4}$ \\
\hline & & & & & & & + & $\mathrm{C}$ \\
\hline \multirow[t]{3}{*}{+} & + & + & + & + & + & + & + & C, F, S, Ro \\
\hline & & + & & & & + & & $\mathrm{R}^{4}, \mathrm{C}, \mathrm{F}, \mathrm{S}, \mathrm{Sp}$ \\
\hline & & & & & & & + & $\mathrm{C}$ \\
\hline \multirow[t]{3}{*}{+} & & & & & & & & $\mathrm{S}$ \\
\hline & & + & & & & & & $\mathrm{R}^{4}$ \\
\hline & & + & & & & & & $\mathrm{R}^{4}$ \\
\hline \multirow[t]{2}{*}{+} & & & & & & & & $\mathrm{S}$ \\
\hline & & + & & & & & & $\mathrm{Ro}^{4}$ \\
\hline
\end{tabular}

${ }^{1} \mathrm{R}=$ Rosi et al., 1994; C = Charoenchai, et al., 1997; F = Fernández et al., 2000; S = Strauss et al., 2001; Sp = Spagna et al., 2002 ; Ro = Rodriguez et al., 2004, and $\mathrm{B}=$ Bolumar et al., 2005.

${ }^{2}$ No teleomorph.

${ }^{3}$ No anamorph.

${ }^{4}$ Only screened for $\beta$-glucosidase activity.

Therefore, reducing the temperature can lead to greater contribution by non-Saccharomyces species. K. apiculata, for example, is able to ferment better at $10^{\circ} \mathrm{C}$ than at $25^{\circ} \mathrm{C}$ (Heard \& Fleet, 1988; Bilbao et al., 1997). The ethanol tolerance of some nonSaccharomyces yeasts, e.g. C. stellata and K. apiculata, is also improved at lower temperatures (e.g. $10^{\circ} \mathrm{C}$ compared with $25^{\circ} \mathrm{C}$ ) (Gao \& Fleet, 1988). Other non-Saccharomyces yeasts, e.g. H. guilliermondii already have an ethanol tolerance very similar to $S$. cerevisiae, however, this is influenced by prior growth conditions (Pina et al., 2004). Reducing the fermentation temperature, with its synergistic effect on ethanol tolerance, will therefore lead to an increased presence of non-Saccharomyces yeasts. This change in the ecology of the fermentation will also result in a change in the concentration of aroma and flavour metabolites formed by the non-Saccharomyces yeasts, with a consequential impact on wine quality.

While it has generally been accepted that $\mathrm{SO}_{2}$ added to wine suppresses non-Saccharomyces yeasts, the work of Henick-Kling et al. (1998), Constantí et al. (1998), Egli et al. (1998) and Rementeria et al. (2003) challenges this belief. Low sulphur addition $(20 \mathrm{mg} / \mathrm{L})$ does not suppress non-Saccharomyces yeasts, higher levels (50 mg/L) do suppress some, but others, e.g. C. guilliermondii and Zygosaccharomyces spp., can survive. The effectiveness of $\mathrm{SO}_{2}$ also depends on the type of must and the number of non-Saccharomyces yeasts present in the first place. Results of Fleet (1990) and Granchi et al. (1998) support this. They found that $\mathrm{SO}_{2}$ in the range 50 to $100 \mathrm{mg} / \mathrm{L}$ did not prevent growth of non-Saccharomyces yeasts in red wine fermentations, but these concentrations are normally effective in white wine fermentations. Suppression of sensitive yeasts by $\mathrm{SO}_{2}$ allows more tolerant yeasts, present in lower numbers, to proliferate. The judicious use of $\mathrm{SO}_{2}$ can therefore alter the non-Saccharomyces population profile in some instances. In other instances, the addition of $\mathrm{SO}_{2}$ will decrease some populations, but not the species diversity (Rementeria et al., 2003).

Other factors that can impact on the presence and growth of non-Saccharomyces yeasts are yeast-yeast and yeast-bacteria interactions, including neutralism, commensalism, mutualism/ synergism, amensalism or antagonism and competition (Boddy \& Wimpenny, 1992; Boulton et al., 1996; Henick-Kling et al., 1998; Fleet, 2003). The utilisation of specific nutrients, e.g. amino acids and vitamins, by one species may make the environment less favourable to other species. In addition, metabolites produced, such as ethanol, inhibitory peptides, proteins and glyco-proteins, can inhibit or destroy other species by lysis of their cell walls. Specifically, zymocidal strains of $S$. cerevisiae (killer yeasts) can affect other species. Other metabolites can, in turn, lead to enhanced growth. Autolysis, with the subsequent release of cellu- 
lar material, can also encourage yeast growth (Charpentier et al., 1986; Fleet, 2003).

Growth of non-Saccharomyces yeasts can also be limited by the S. cerevisiae starter culture (Constantí et al., 1998; Henick-Kling et al., 1998). High concentrations of S. cerevisiae appear to inhibit some non-Saccharomyces yeasts by means of a cell-cell mediated mechanism (Nissen et al., 2003). Subsequently, different starter cultures will have different effects on the non-Saccharomyces populations. Therefore, by controlling the parameters of inoculum, i.e. $S$. cerevisiae strain and inoculum concentration, the nonSaccharomyces contribution can also be controlled. This is illustrated by the experiments of Egli et al. (1998). They compared three types of fermentation, i.e. fermentations with indigenous microflora (spontaneous), a vigorous yeast starter ( $S$. cerevisiae strain EC1118) and a slowly fermenting yeast starter (S. cerevisiae strain Assmanshausen). The sensory profiles of the resultant wines differed from each other. The faster growing EC1118 strain limited the growth of the non-Saccharomyces component more strongly than the slow growing Assmanshausen. Growth could be further suppressed by the addition of $\mathrm{SO}_{2}$.

It has also been suggested that the use of fungicides and pesticides results in a reduced yeast presence on grapes (Parish \& Caroll, 1985; Regueiro et al., 1993; Guerra et al., 1999). It has been shown that yeast populations are higher when no agrochemicals have been applied for some time (Renouf et al., 2005). Higher levels of non-Saccharomyces yeasts can impact on the resultant fermentation and wine quality. In contrast, Cabras et al. (1999) showed that certain pesticides could stimulate yeasts (especially $K$. apiculata) to produce more ethanol. This increased vigour would, by implication, also extend to other metabolites. As pesticides are used to a greater or lesser extent in all vineyards (with a few possible exceptions where natural processes are followed), there might be instances where certain pesticides can stimulate non-Saccharomyces growth on the grapes. The resultant higher levels of such yeasts might also have a knock-on effect in the subsequent wine fermentation.

Non-Saccharomyces populations might also be affected by 'quorum sensing', the mechanism whereby microbial cells can communicate with each other and cause a population to follow a specific growth pattern (Bisson, 1999; Fleet, 2003; Parsek \& Greenberg, 2005). Bicarbonate, ammonia and farnesol have been suggested as cell communication molecules for yeast. The effect of quorum sensing and its significance to wine production is not known.

\section{THE USE OF NON-SACCHAROMYCES YEASTS IN WINE PRODUCTION}

A number of authors have reported that the use of selected and cultured non-Saccharomyces yeasts, including Candida, Kloeckera, Brettanomyces and Zygosaccharomyces species, is beneficial in wine production. As these yeasts are all poor fermenters, $S$. cerevisiae (either indigenous or inoculated) is always needed to complete wine fermentation. Typically, nonSaccharomyces yeasts have been used in sequential fermentation where these yeasts are allowed to grow or ferment for between one hour and fifteen days before inoculation with $S$. cerevisiae (Herraiz et al., 1990; Zironi et al., 1993; Ciani \& Ferraro, 1998; Ferraro et al., 2000; Jolly et al., 2003b; 2003c). Unfortunately, some authors only report on experiments conducted on laboratory-scale, utilising small volumes of grape juice. These results are not necessarily the same as what could be expected in larger commercial fermentations. Factors such as small amounts of air which can enter small-volume fermentations during e.g. sampling, and the rapid sedimentation of yeast which reduces fermentation rate, can affect the final results (Henschke, 1990).

\section{Candida stellata}

C. stellata is known as a high glycerol producer and Ciani \& Picciotti (1995) suggested that it be used as a starter culture to increase glycerol levels in wine. Values of up to $11.76 \mathrm{~g} / \mathrm{L}$ have been reported (Ciani \& Maccarelli, 1998), which is higher than the sensory threshold level for glycerol sweetness, i.e. $5.2 \mathrm{~g} / \mathrm{L}$ (Noble \& Bursick, 1984). Glycerol is also thought to contribute to the mouth-feel and complexity of wine flavour, at lower levels (Scanes et al., 1998; Prior et al., 2000). This yeast is therefore a prime candidate for investigating a positive non-Saccharomyces contribution to wine quality.

Ciani \& Ferraro (1998) used a C. stellata strain (strain 3827, Industrial Yeast Collection, University of Perugia) to improve the analytical profile of small-scale $(500 \mathrm{~mL})$ Pinot grigio wines during batch fermentations. The Pinot grigio grapes were harvested at $18.5^{\circ} \mathrm{B}$ and sweetened to $27^{\circ} \mathrm{B}$ with sucrose. Immobilised C. stellata cells at concentrations of $1 \times 10^{9}$ cells $/ \mathrm{mL}$ were used in three fermentation types: a simultaneous inoculation with $S$. cerevisiae; a sequential fermentation where $S$. cerevisiae was added three days after $C$. stellata; and a substituted fermentation where $C$. stellata was replaced with $S$. cerevisiae after three days. The $S$. cerevisiae inoculum was $1 \times 10^{6}$ cells $/ \mathrm{mL}$ for all treatments. Results showed that in comparison to the $S$. cerevisiae control fermentations, the combined fermentations occurred more rapidly with increased glycerol content. This was accompanied by a decrease in acetic acid and higher alcohols and an increase in succinic acid. Other by-products were similar to those found in the $S$. cerevisiae control fermentation. Despite the high initial sugar content, all of the sugar was consumed due to the complementary utilisation of fructose and glucose by the $C$. stellata (fructophilic yeast) and $S$. cerevisiae (glucophilic yeast). It was concluded that of all three treatments, the sequential fermentation was the best combination for improving the analytical profile of the wines. It was further noted that acetoin produced by $C$. stellata was utilised by $S$. cerevisiae to form 2,3-butanediol that can lead to off-flavour in wine. As no sensory analyses were carried out it is not clear what impact this had on the flavour of the wine.

In a subsequent study, Ferraro et al. (2000) confirmed the above findings in the pilot-scale $(100 \mathrm{~L})$ production of wine. They used Trebbiano Toscano grape juice at $19^{\circ} \mathrm{B}, \mathrm{pH} 2.94$ and $11.52 \mathrm{mg} / \mathrm{L}$ free $\mathrm{SO}_{2}$. The inoculum of immobilised $C$. stellata $\left(5 \times 10^{8}\right.$ cells $\left./ \mathrm{mL}\right)$ was followed after three days by an inoculum of $S$. cerevisiae $\left(5 \times 10^{6}\right.$ cells $/ \mathrm{mL}$ ). High glycerol production was evident on the fourth day of fermentation, while the alcohol was still lower than 5\%. Thereafter, the glycerol production was slower and the ethanol concentration increased due to metabolism by S. cerevisiae. The final wine had a $70 \%$ higher glycerol concentration than the control ( $S$. cerevisiae only), while the ethanol concentration was $10.6 \%$ compared with the $12.24 \%$ of the control. The acetic acid was $0.05 \mathrm{~g} / \mathrm{L}$ lower than the control fermentation. 
Apart from the increase in glycerol, the reduction in alcohol as reported above could be beneficial for the production of wines from grapes with high sugar content (as often found in grapes from warm regions). Reduction in acetic acid concentration will always be beneficial. However, while the analytical profile of the wine was improved, a shortcoming of the work of Ferraro et al. (2000) is that they did not report on the sensory profile of the wine. During the three-day lag before inoculation with $S$. cerevisiae, oxidation of the must might have occurred. However, spontaneous fermentation would have started and this might have offset the oxidation risk.

In another investigation Soden et al. $(1998 ; 2000)$ used C. stellata in combination with $S$. cerevisiae for the production of Chardonnay wines. They used two different inoculation protocols, viz. co-inoculation and sequential inoculation, starting with the $C$. stellata, and these were compared with the two yeasts in separate monoculture ferments. The yeasts were inoculated at a concentration of $5 \times 10^{6}$ cells $/ \mathrm{mL}$, except in the co-inoculated fermentation where the $S$. cerevisiae was inoculated at a lower cell count $\left(5 \times 10^{5}\right.$ cells $\left./ \mathrm{mL}\right)$. In the sequential fermentation, $S$. cerevisiae was inoculated 15 days after $C$. stellata. At this point the C. stellata had depleted the fructose, but not the glucose, and had stopped fermenting. All the wines except the $C$. stellata monoculture fermented dry.

The wines underwent descriptive sensory analyses and the reference $S$. cerevisiae wine was judged to have 'tropical fruit', 'floral', 'lime' and 'banana' aromas of a typical Chardonnay. The monoculture C. stellata wine had significantly more 'apricot', 'honey' and 'sauerkraut' aromas and significantly less 'lime', 'tropical fruit', 'banana' and 'floral' aromas. The co-inoculated wine had aromas similar to wine resulting from use of the $S$. cerevisiae monoculture, but was scored lower for 'floral' and 'banana'. The sequential fermentations produced a wine significantly different from the $S$. cerevisiae reference wine regarding 'banana', 'floral' and 'lime' aromas, but the wine was similar in the 'honey', 'apricot' and 'sauerkraut' aromas attributed to the C. stellata yeast. The wine also had a high 'ethyl acetate' aroma, had the highest concentration of glycerol and succinic acid, and a lower concentration of ethanol. On the negative side, 'sauerkraut' and 'ethyl acetate' nuances could be considered to detract from wine quality as they are listed under 'microbiological' and 'oxidised' according to wine evaluation terminology (Noble et al., 1987). The long time lapse of 15 days before the inoculation with $S$. cerevisiae in the sequential fermentation would have contributed to the 'oxidised' aroma of the wine. A shorter delay before inoculation with $S$. cerevisiae could have given a better wine. Soden et al. (2000) concluded that, with selection of the appropriate strains and the establishment of effective inoculation protocols, greater flavour diversity and complexity could be obtained in wine during commercial winemaking.

In another study where $C$. stellata and $S$. cerevisiae were used in sequential fermentations for the production of small-scale Chardonnay wines, the time lapse between inoculations of the two species was only one hour (Jolly et al., 2003b). No increases in glycerol levels were noted, as was the case when the $C$. stellata isolate was used on its own in laboratory-scale fermentations. For the small-scale Chardonnay wine, the total esters was significantly higher for the $C$. stellata sequential wine in comparison to the $S$. cerevisiae only reference wine. However, during a comparative sensory evaluation the reference wine was preferred. No descriptive sensory analysis was performed.

\section{Candida pulcherrima}

C. pulcherrima, which produces high concentrations of esters (Bisson \& Kunkee, 1991), especially the pear-associated ester ethyl caprylate (Lambrechts \& Pretorius, 2000; Clemente-Jimenez et al., 2004), can occur in high numbers in grape must (Schütz \& Gafner, 1993; Jolly et al., 2003a). Furthermore, it was shown by Zohre \& Erten (2002) that production of undesirable volatile compounds did not occur during mixed culture fermentations of this yeast and $S$. cerevisiae. $C$. pulcherrima might therefore make a positive sensory contribution to wine. In another study, a randomly selected $C$. pulcherrima isolate was used in sequential fermentations with $S$. cerevisiae, for small-scale production of Chardonnay, Sauvignon blanc and Chenin blanc wines (Jolly et al., 2003b). A sensory evaluation of the wines showed that Sauvignon blanc and Chenin blanc were better than a reference wine ( $S$. cerevisiae only) five and 18 months after production. The Chardonnay wine was judged to be of an inferior quality. It thus appears that there are specific non-Saccharomyces/grape variety combinations that lead to improved quality.

In a subsequent study, the effect of winemaking practices (namely the use of diammonium phosphate [DAP] and $\mathrm{SO}_{2}$ ), fermentation temperatures and must $\mathrm{pH}$ on the performance of C. pulcherrima during fermentation was investigated (Jolly et al., 2003c). It was reported that DAP addition, higher $\mathrm{pH}$ values and increased temperatures all resulted in a slight increase in fermentation ability. The fermentation ability was not affected by $\mathrm{SO}_{2}$ concentrations normally used in wine fermentation $(0-30 \mathrm{mg} / \mathrm{L})$. Elevated levels $(60 \mathrm{mg} / \mathrm{L})$ of $\mathrm{SO}_{2}$ did have a negative effect, however, this is a much higher concentration than would normally be used in a commercial fermentation. A Chenin blanc wine production trial showed that a selected $C$. pulcherrima strain had a positive influence on wine quality (as measured by a sensory panel). No difference in standard chemical analyses was noted and the improvement was not linked to ester levels; the authors implicated other metabolites, but further chemical analyses and suitable methodology were required to identify them.

\section{Kloeckera and Hanseniaspora spp.}

The apiculate yeasts $K$. apiculata and $H$. uvarum, the nonSaccharomyces yeasts found in the highest numbers in grape must, are in the best position to make a contribution to wine quality. These yeasts, with low fermentative power, are important in the production of volatile compounds in wine, and the chemical composition of wines made with Kloeckera spp./S. cerevisiae combinations differ from reference wines (Herraiz et al., 1990; Mateo et al., 1991; Zironi et al., 1993; Gil et al., 1996).

Caridi \& Ramondino (1999) evaluated a range of 20 Hanseniaspora spp. (Kloeckera spp.) of oenological origin for their ability to ferment a must $\left(17.9^{\circ} \mathrm{B} ; \mathrm{pH} 3.81\right)$. They found that the ethanol produced ranged from 5.02 to $8.72 \%$, in comparison to the $11.17 \%$ of the control ( $S$. cerevisiae), but volatile acidity was higher $(0.75 \mathrm{~g} / \mathrm{L}$ to $2.25 \mathrm{~g} / \mathrm{L})$ than the control $(0.65 \mathrm{~g} / \mathrm{L})$. These results indicate that although some strains of Hanseniaspora are able to produce higher levels of ethanol than other strains, the high levels of volatile acidity would be detrimental to the senso- 
ry characteristics of the wine. However, Romano et al. (1992) and Ciani \& Maccarelli (1998) showed that not all Kloeckera strains formed high levels of volatile acidity and that some were similar to $S$. cerevisiae in this regard. The production of other secondary metabolites, i.e. glycerol, acetaldehyde, ethyl acetate and hydrogen sulphide, also differed between strains (Romano et al., 1997). Selected strains of apiculate yeasts might therefore favour aroma and flavour enhancement in wines.

Most authors working with these yeasts only utilised Kloeckera spp. in small-scale laboratory trials and subsequently only analysed the wines chemically. Their approaches to the use of Kloeckera also differed. Zironi et al. (1993), in their sequential fermentations, allowed a Kloeckera/Hanseniaspora ferment to go for six days before inoculating with $S$. cerevisiae, while Herraiz et al. (1990) waited eight days. Differences in chemical analyses of the wines were noted. Of more concern was that the initial growth of Kloeckera had a retarding effect on the subsequent growth of $S$. cerevisiae. This phenomenon could have further implications as a cause for lagging or stuck fermentations. Therefore, a cautionary approach would have to be taken when considering using Kloeckera spp. in wine production. K. apicula$t a$ has also been implicated in the formation of some biogenic amines (Caruso et al., 2002).

Sensory evaluations on wines produced by Kloeckera spp. were carried out by Owuama \& Saunders (1990). They used K. apicula$\mathrm{ta} / \mathrm{S}$. cerevisiae combinations for the fermentation of cashew apple juice $\left(25^{\circ} \mathrm{B}\right)$. Inoculation of the two species was simultaneous and $9.3 \%$ ethanol was produced with $4.2 \%$ residual sugar. Sensory evaluation (colour, aroma and taste) of the wines showed that although the Saccharomyces reference wine was the best, the product of the combined fermentation was also acceptable for consumption.

A $K$. apiculata isolate was also used with S. cerevisiae for the production of small-scale Chardonnay, Sauvignon blanc and Chenin blanc wines (Jolly et al., 2003b). Inoculation of the $S$. cerevisiae was one hour after that of the $K$. apiculata and $c a$. $13 \%$ ethanol was produced with less than $2 \mathrm{~g} / \mathrm{L}$ residual sugar. Sensory evaluation of the wines five and 18 months after production showed that the Sauvignon blanc wine was preferred by the judges. All the other wines were judged to be inferior to a reference wine produced by $S$. cerevisiae only.

The production of 2-phenyl-ethyl acetate by the apiculate yeast $H$. guilliermondii has been investigated in laboratory fermentations (Rojas et al., 2003). This acetate ester contributes to 'rose', 'honey', 'fruity' and 'flowery' aroma nuances (Lambrechts \& Pretorius, 2000; Swiegers \& Pretorius, 2005; Swiegers et al., 2005), and is formed to a greater or lesser extent by most yeasts. As part of the 'fermentation bouquet', it can contribute to the overall flavour of a young wine. However, the high level of ethyl acetate produced by the strain investigated by Rojas et al. (2003) was a serious handicap.

Another role that has been suggested for Kloeckera and Hanseniaspora spp. is that of the production of wine destined for vinegar manufacture (Ciani \& Picciotti, 1995). The high production of acetoin and ethyl acetate will favourably influence the quality of vinegar.

\section{Zygosaccharomyces spp.}

Zygosaccharomyces spp. are considered to be winery contaminants and are especially a problem in wineries producing sweet and sparkling wines (Amerine \& Cruess, 1960; Loureiro \& Malfeito-Ferreira, 2003). Notwithstanding, Zygosaccharomyces spp. have been investigated by Romano \& Suzzi (1993a) as positive contributors to wine fermentation. The species studied included a $Z$. fermentati strain (strain F42), which produced low levels of acetic acid, $\mathrm{H}_{2} \mathrm{~S}$ and $\mathrm{SO}_{2}$ and had high fermentation vigour. Another species, Z. bailii (strain F37), showed malic acid degradation and generally low $\mathrm{H}_{2} \mathrm{~S}$ production. In addition, both species flocculated. The authors suggested that these characteristics could benefit wine production during, for example, re-fermentation of wine.

Most of the literature recognises Zygosaccharomyces yeasts as spoilage organisms producing high quantities of acetic acid. However, Romano \& Suzzi (1993a) suggested that this acetic acid production might be due to yeasts bearing a close resemblance to Zygosaccharomyces. In older literature, acetic acid-producing yeasts were wrongly identified as Zygosaccharomyces species.

Selected strains of Zygosaccharomyces spp. might be useful especially for the production of alternate beverages. Z. bailii is also, in contrast to many other non-Saccharomyces yeasts and $S$. cerevisiae, fructophilic. This could be beneficial in grape musts from riper grapes (high Balling), where the fructose concentration can exceed that of glucose at the start of fermentation (Margalith, 1981).

\section{Schizosaccharomyces spp.}

Schizosaccharomyces spp. have been used for the production of mango (Magnifera indida L.) wine without addition of $S$. cerevisiae (Obisanya et al., 1987). Two strains of Schizosaccharomyces spp. isolated from palm wine were found to be suitable for the production of sweet mango table wine with between 8 and $9 \%$ alcohol. Reference wines produced by $S$. cerevisiae were, however, found to be superior in flavour and taste, while fermenting dry (approximately $4 \mathrm{~g} / \mathrm{L}$ sugar).

Another characteristic of Schizosaccharomyces spp. is their ability to degrade malic acid; it has been shown that high-density cell suspensions of Schizosaccharomyces yeasts could degrade 95-99\% of malic acid in a buffered assay system (Gao \& Fleet, 1995). However, none of the yeasts could metabolise malic acid fast enough to be of use in a reactor system for the treatment of grape juice. Increasing the cell density had no improved effect.

In another trial, a Schizosaccharomyces malidevorans mutant that could utilise malic acid more rapidly than the wild-type strain was used for commercial-scale (1000 to $2500 \mathrm{~L}$ ) deacidification of grape juice (Thornton \& Rodriguez, 1996). The varieties treated were Chardonnay, Semillon and Cabernet Sauvignon. The temperature and $\mathrm{SO}_{2}$ levels were those normally applied in wine production, i.e. $15-25^{\circ} \mathrm{C}$ and $30 \mathrm{mg} / \mathrm{L}$ (free), respectively. No sensory defects were noted in the finished wines, which were used for blending, before being sold as varietal wines.

\section{Torulaspora delbrueckii}

T. delbrueckii (teleomorph of C. colliculosa), formerly classified as Saccharomyces rosei, was previously suggested for vinification of musts low in sugar and acid (Castelli, 1955). It was subsequently used for the commercial production of red and rosé wines in Italy (Castelli, 1955). In more recent experiments carried out by Moreno et al. (1991) it was found that T. delbrueckii in 
pure culture produced lower levels of volatile acidity than the $S$. cerevisiae strains tested. Furthermore, in mixed fermentations (indigenous population plus pure cultures of $T$. delbrueckii or $S$. cerevisiae) the volatile acidity increased with the ripeness of the grapes, however, these increases were generally smaller for the $T$. delbrueckii than the $S$. cerevisiae strains.

In another investigation, the anamorphic form of this yeast (C. colliculosa) was used together with $S$. cerevisiae for the production of small-scale Chardonnay, Sauvignon blanc and Chenin blanc wines (Jolly et al., 2003b). The Sauvignon blanc and Chenin blanc wines were both judged to be better than their respective $S$. cerevisiae reference wines five and 18 months after production. However, standard wine chemical and ester analyses did not differ from the reference wines.

\section{Brettanomyces spp.}

The contribution of Brettanomyces spp. to wine aroma has been likened to a 'Bordeaux-like' character. Apart from the previously mentioned negative aroma nuances imparted by these yeasts, positive aromas such as 'smoky', 'spicy' and 'toffee' are also cited (Eschenbruch \& Wong, 1993; Arvik \& Henick-Kling, 2002). Brettanomyces spp. have also been implicated in Belgian acidic ale production where it is found in the final 20 to 24 month stage in the fermentation casks (Martens et al., 1997). While the deliberate inoculation of Brettanomyces in must or wine for commercial production has not been reported, some winemakers are working with the indigenous populations of Brettanomyces found in their cellars to make more complex wines, some of which are highly regarded because of their aromas and flavours (Arvik \& Henick-Kling, 2002). This topic is being investigated by different research groups (Grbin \& Henschke, 2000; Arvik \& HenickKling, 2002) and a favourable Brettanomyces strain or protocol for the beneficial use of Brettanomyces spp. for wine production might still be found. However, the formation of 'mousy' and 'medicinal' off-flavour compounds will have to be controlled. Strain selection will also have to ensure that no biogenic amines are produced (Caruso et al., 2002).

\section{Saccharomycodes ludwigii}

S. ludwigii is a lesser known, lemon-shaped yeast, typically with a large cell size, frequently isolated from wine at the end of fermentation or from wine in storage (Romano et al., 1999). Secondary metabolites produced at high levels by this yeast include isobutyl alcohol, acetoin and ethyl acetate. It is also known to be highly resistant to $\mathrm{SO}_{2}$ and tolerant to ethanol. A selected strain of $S$. ludwigii was used to ferment feijoa or pineapple guava (Feijoa sellowiana) juice. The resultant beverage was evaluated for aroma, flavour and taste by a consumer panel. Despite the high levels of acetic acid, the beverage was described as "fresh" with a "fruity flavour", akin to apple and kiwi, and similar to apple juice in taste, but with more acid. Romano et al. (1999) concluded that this beverage had potential as a refreshing summer drink.

\section{Kluyveromyces thermotolerans}

A commercial active dried yeast blend of $K$. thermotolerans and S. cerevisiae (Viniflora ${ }^{\circledR}$ SYMPHONY.nsac) has recently been released (Anon., 2004a). This combination has been developed for the enhancement of aroma and flavour in white (Chardonnay, Pinot blanc, Pinot gris and Riesling) and red (Cabernet
Sauvignon, Merlot, Shiraz and Pinot noir) grape varieties. According to the product information sheet, the use of this yeast in simultaneous inoculations can lead to the enhancement of floral and tropical fruit aromas, and more complex and rounded flavours in white and red wine, respectively. Although the ratio of the $K$. thermotolerans to $S$. cerevisiae is not specified, it appears to be in the region of 1:30 (Jolly, unpublished data, 2005).

\section{Other non-Saccharomyces spp.}

Other non-Saccharomyces yeasts that have also been investigated for their potential contribution to wine include Pichia and Williopsis spp.

The production of 2-phenylethanol by Pichia fermentans has been investigated under optimised culture conditions by Huang et al. (2001). This alcohol, contributing to an aroma of rose petals, is formed to a greater or lesser extent by most yeasts, and as part of the 'fermentation bouquet' can contribute to the overall flavour of a young wine. It was found that the production of this compound increased with an increase in biomass during the initial stage of fermentation. A maximum concentration was reached after 16 hours.

The use of $P$. fermentans was also investigated by ClementeJimenez et al. (2005) in microvinifications $(250 \mathrm{~mL})$. It was found that mixed fermentations with $S$. cerevisiae resulted in an increase in some aromatic compounds such as acetaldehyde, ethyl acetate, 1-propanol, n-butanol, 1-hexanol, ethyl caprylate, 2,3-butanediol and glycerol.

Other Pichia spp., i.e. P. anomala, P. membranifaciens and P. subpelliculosa, together with Williopsis saturnus have also been suggested for the production of low-alcohol wines ( $\mathrm{ca}$. $3 \% \mathrm{v} / \mathrm{v}$ ) in an aerated vessel (Erten \& Camphill, 2001). In this method stirring and agitation resulted in more yeast biomass being formed and decreased ethanol production from fermentable sugars. The wines, made by $P$. subpelliculosa and $W$. saturnus in particular, were acceptable to a small tasting panel. This method of low-alcohol wine production eliminates the need for costly and complex post-production removal of alcohol from wines produced during normal fermentations. The higher levels of flavour compounds, especially esters, produced by these aerobic yeasts appeared to counteract the loss of flavour enhancing properties of alcohol. The "body" of the wine normally attributed to ethanol also appeared to have been replaced by the higher concentration of esters.

The demand by the beverage industry for new and interesting products and the well-developed flavour produced by aerobic non-Saccharomyces yeasts makes this technology attractive. However, problems envisioned are the need for non-standard fermentation equipment and the reluctance of wine and beverage producers to deliberately cultivate organisms normally considered as contaminants.

The early death of some non-Saccharomyces yeasts during fermentation can also be a source of specific nutrients for $S$. cerevisiae, enabling it to ferment optimally. These nutrients include cellular constituents such as cell wall polysaccharides (mannoproteins). For this method of nutrient supply to be effective, any killer or other inhibitory effects by the non-Saccharomyces yeasts against S. cerevisiae should be known (Herraiz et al., 1990; Panon, 1997; Nguyen \& Panon, 1998; Fleet, 2003) so that the subsequent $S$. cerevisiae fermentation is not adversely affected. 


\section{Combinations of non-Saccharomyces yeasts}

Eschenbruch \& Wong (1993) inoculated a red grape variety (Blauburger) with a combination of the non-Saccharomyces yeasts Kloeckera sp. and Brettanomyces sp. This was followed after 24 hours with a $S$. cerevisiae pure culture. These authors reported that the wine developed an overall flavour and complexity that they termed a "Brettanomyces" character. This character, they maintained, was a direct result of the contribution of the Kloeckera sp. and Brettanomyces sp. They reported further that a lower cell concentration should be used as higher cell concentrations $\left(10^{6}\right.$ cells $\left./ \mathrm{mL}\right)$ resulted in off-characters. Their control fermentations showed an indigenous population of Kloeckera and Candida yeasts, but the numbers of these declined and essentially disappeared as the fermentation proceeded. No Brettanomyces yeasts were detected. After inoculation of the control, the $S$. cerevisiae yeast quickly became the predominant species. This was also noted in the non-Saccharomyces inoculated fermentations. The numbers of Candida sp. once again decreased as the fermentation proceeded. However, the cell densities of the Brettanomyces and Kloeckera (represented by the added yeasts and indigenous yeasts already present) decreased only slightly during the fermentation. These yeasts therefore could contribute towards the fermentation metabolism, resulting in a contribution to taste and flavour differences.

In another investigation with combinations of nonSaccharomyces yeasts, T. delbrueckii was used in sequential fermentations with $K$. apiculata. The $K$. apiculata was inoculated first, followed three days later by $T$. delbrueckii, and finally $S$. cerevisiae was inoculated after eight days. The wines produced had volatile compositions different from the $S$. cerevisiae wines, but were not subjected to sensory evaluation (Herraiz et al., 1990).

Another commercial active dried wine yeast culture (Viniflora ${ }^{\circledR}$ HARMONY.nsac) combines the non-Saccharomyces yeasts $T$. delbrueckii and $K$. thermotolerans with S. cerevisiae (Anon., $2004 b$ ). According to the technical data sheet this combination (simultaneous inoculation) leads to wines with a richer and rounder flavour with enhanced fruity notes. Improvements in wine quality have been observed for a number of white (Chardonnay, Pinot blanc, Pinot gris, Riesling) and red grape varieties (Cabernet Sauvignon, Pinot noir, Shiraz, Merlot). The proportion of the three different yeasts to each other is not disclosed, but the non-Saccharomyces to $S$. cerevisiae ratio appears to be in the region of 1:14 (Jolly, unpublished data, 2005).

\section{RESEARCH TRENDS IN RELATION TO NON-SACCHARO- $M Y C E S$ YEASTS}

The utilisation of non-Saccharomyces yeasts such as C. stellata, T. delbrueckii and others to improve the analytical profile and flavour of wines has already been discussed. Concurrently with the envisioned use of these new "wine yeasts", new fermentation techniques could be implemented and alternative alcoholic beverages produced (Ciani \& Maccarelli, 1998). It has already been shown that non-Saccharomyces yeasts normally found during wine fermentation are also responsible for the fermentation of Kombucha, a traditional beverage produced by fermenting sweetened black tea (Teoh et al., 2004). Non-Saccharomyces isolates from wine could therefore be screened for improved strains for Kombucha production.
It has also been shown that $S$. cerevisiae can initiate biofilm formation (Reynolds \& Fink, 2001), a characteristic previously thought to be restricted to bacteria (Parsek \& Greenberg, 2005). This has implications for wine fermentation and the storage of wines. The ability of wine-related non-Saccharomyces to form biofilms is not well researched, but it has been suggested that yeast cells on the surfaces of grape berries may interact in a biofilm system (Renouf et al., 2005). It is also known that C. albicans, previously isolated from grapes (Parish \& Caroll, 1985), forms biofilms which contribute to its pathogenesis (Douglas, 2003). It can therefore be speculated that other non-Saccharomyces yeasts, even if unable to initiate biofilms themselves, may become constituents of a $S$. cerevisiae or C. albicans biofilm and, in so doing, contribute positively or negatively to wine production.

As $S$. cerevisiae is glucophilic (a preference for glucose above fructose) (Ough \& Amerine, 1963; Margalith, 1981; Berthels et al., 2004), the use of fructophilic non-Saccharomyces yeasts has also been suggested for the remediation of some types of sluggish or stuck fermentations (Gafner et al., 2000). Should the glucose be utilised faster than the fructose during a 'normal' fermentation, then a glucose-fructose imbalance can occur and $S$. cerevisiae is unable to ferment further. Under these circumstances fructophilic yeasts, e.g. C. stellata and Z. bailii, which have a preference for fructose, can be used to metabolise the fructose (Sütterlin et al., 2004). Once the glucose-fructose balance is restored, S. cerevisiae should start fermenting again. An active dried experimental $Z$. bailii strain has already been produced and is currently being evaluated by commercial wine cellars (P. Loubser, Lallemand, South Africa, personal communication, 2006). This technology holds great potential as sluggish and stuck fermentations are a common occurrence in all wine industries.

In another study, killer toxins from $P$. anomala and Kluyveromyces wickerhamii have been investigated as antimicrobial agents against the spoilage yeast Dekkera/Brettanomyces (Comitini et al., 2004). This has a potential application during wine maturation and storage.

Apart from the investigations and experimentation with nonSaccharomyces yeasts in wine production, other uses for nonSaccharomyces yeasts and their metabolites are being sought. These include the use of Pichia pastoris for the biomodification of citrus aroma oil to improve and add value to the essence (Goodrich et al., 1998). A protease enzyme isolated from $D$. hansenii has also been suggested for hydrolysis of muscle proteins during meat processing (Bolumar et al., 2005).

Another application for non-Saccharomyces yeasts is the use of Zygocin, a protein toxin produced and secreted by killer strains of Z. bailii (Weiler \& Schmitt, 2003). Purified forms of the toxin have potential as an antimycotic for a variety of human and phytopathogenic fungi (Schmitt \& Breinig, 2002). The use of nonSaccharomyces as bio-control alternatives to chemicals has also been investigated. A "sister" species to M. pulcherrima (teleomorph of C. pulcherrima), Metschnikowia fructicola isolated from grapes, shows activity against botrytis rot on stored grapes (Kurtzman \& Droby, 2001), while in vitro experiments show that $P$. membranifaciens is antagonistic towards the causative agent, Botrytis cinerea (Masih et al., 2001). Table grape storage and post harvest damage due to botrytis is a major problem in grape-producing regions that lie far from their respective domestic and 
international markets. The possible use of Pichia guilliermondii for copper uptake in bio-remediation of sewage sludge has also been suggested (De Silóniz et al., 2002). Considering the wide biodiversity of yeasts found on grapes and in must, the potential for finding yeasts benefiting mankind outside the parameters of wine production is large.

\section{FINAL COMMENTS}

It is generally accepted that the wealth of yeast biodiversity with hidden potential, especially for oenology, is largely untapped (Pretorius, 2000). However, in order to exploit the potential benefits of non-Saccharomyces yeasts in wine production and to minimise potential spoilage, the yeast populations on grapes and in must, as well as the effect of wine making practices on these yeasts, must be known, as must the metabolic characteristics of non-Saccharomyces yeasts (Romano et al., 2003). This knowledge will help realise the predictions of Heard (1999) concerning the use of mixed starter cultures. His vision includes the use of mixed yeast starter cultures tailored to reflect the characteristics of a given wine region and the use of indigenous yeast species with modern technology to produce novel wine-based beverages.

Strain selection will be very important, as not all strains within a species will necessarily show the same desirable characteristics. For example, significant variability is found in the formation of undesirable biogenic amines amongst strains within some nonSaccharomyces yeast species (Caruso et al., 2002).

Whatever the outcome of the search for non-Saccharomyces yeasts for use in wine production, the accepted list of desirable characteristics as pertaining to the wine yeast $S$. cerevisiae (Yap, 1987; Henschke, 1997; Pretorius, 2000) will not necessarily apply to non-Saccharomyces yeasts. High fermentation efficiency, high sulphite tolerance and zymocidal (killer) properties, for example, might not be needed in the new technology of wine production. The new non-Saccharomyces wine yeasts will necessarily have a different list of desired characteristics. Furthermore, the already mentioned problems envisioned by Erten \& Campbell (2001) regarding the need for non-standard fermentation equipment and the reluctance of wine producers to cultivate and use, on a large-scale, microorganisms generally considered as spoilage organisms (Loureiro \& Malfeito-Ferreira, 2003), should be noted. Intensive education will have to accompany any new nonSaccharomyces technology in wine production. However, the goals as set out by Pretorius (2000; 2003) regarding efficient sugar utilisation, enhanced production of desirable volatile esters, enhanced liberation of grape terpenoids and production of glycerol to improve wine flavour and other sensory properties can be met by selected non-Saccharomyces wine yeasts. This path will bypass current controversies regarding the genetic modification of the workhorse of wine production, i.e. the "wine yeast" S. cerevisiae. After the acceptance of genetically modified organisms (GMO) by wine consumers and industries, genetic modification of selected non-Saccharomyces yeasts can further enhance their performance and role in wine production.

\section{LITERATURE CITED}

Amerine, M.A. \& Cruess, W.V., 1960. The technology of winemaking. The AVI Publishing Company, Inc., Connecticut.

Amerine, M.A., Berg, H.W. \& Cruess, W.V., 1967. The technology of winemaking (2nd ed). The AVI Publishing Company, Inc., Connecticut.
Amerine, M.A., Berg, H.W. \& Cruess, W.V., 1972. The technology of winemaking (3rd ed). The AVI Publishing Company, Inc., Connecticut.

Anonymous, 2004a. Viniflora ${ }^{\circledR}$ SYMPHONY.nsac product information. Chr. Hansen A/S, 10-12 Bøge Allé, DK-2970 Hørsholm, Denmark.

Anonymous, 2004b. Viniflora ${ }^{\circledR}$ HARMONY.nsac product information. Chr. Hansen A/S, 10-12 Bøge Allé, DK-2970 Hørsholm, Denmark.

Arvik, T. \& Henick-Kling, T., 2002. Brettanomyces bruxellensis occurrence, growth, and effect on wine flavour. Prac. Winery Vin. 24, 48-56.

Berthels, N.J., Cordero Otero, R.R., Bauer, F.F., Thevelein, J.M. \& Pretorius, I.S., 2004. Discrepancy in glucose and fructose utilisation during fermentation by Saccharomyces cerevisiae wine yeast strains. FEMS Yeast Res. 4, 683-689.

Bilbao, A., Irastorza, A., Dueñas, M. \& Fernandez, K., 1997. The effect of temperature on the growth of strains of Kloeckera apiculata and Saccharomyces cerevisiae in apple juice fermentation. Lett. Appl. Microbiol. 24, 37-39.

Bisson, L.F., 1999. Stuck and sluggish fermentations. Am. J. Enol. Vitic. 50, 107-119.

Bisson, L.F. \& Kunkee, R.E., 1991. Microbial interactions during wine production. In: Zeikus, J.G. \& Johnson, E.A. (eds). Mixed cultures in biotechnology, McGraw-Hill, Inc., New York. pp. 39-68.

Boddy, L. \& Wimpenny, J.W.T., 1992. Ecological concepts in food microbiology. J. Appl. Bacteriol. 73, 235-385 (supplement).

Bolumar, T., Sanz, Y., Aristoy, M-C. \& Toldra, F., 2005. Protease B from Debaryomyces hansenii: purification and biochemical properties. Int. J. Food. Microbiol. 98, 167-177.

Boulton, R.B., Singleton, V.L., Bisson, L.F. \& Kunkee, R.E., 1996. Principles and practices of winemaking. Chapman \& Hall, New York.

Cabras, P., Angioni, A., Garau, V.L., Pirisi, F.M., Farris, G.A., Madau, G. \& Emonti, G., 1999. Pesticides in fermentative processes of wine. J. Agric. Food Chem. 47, 3854-3857.

Cansado, J., Longo E., Agrelo, D. \& Villa, T.G., 1989. Levaduras asociadas a procesos de fermentación espontánea en vinos de Ribeiro. Análisis del homo/heterotalismo y sistema killer de las cepas de S. cerevisiae. Microbiologia 5, 79-88.

Caridi, A. \& Ramondino, D., 1999. Biodiversita' fenotipica in ceppi di Hanseniaspora di origine enologica. Enotecnico 45, 71-74.

Carrau, F.M., Medina, K., Boido, E., Farina, L., Gaggero, C., Dellacassa, E., Versini, G. \& Henschke, P.A., 2005. De novo synthesis of monoterpenes by Saccharomyces cerevisiae wine yeasts. FEMS Microbiol. Lett. 243, 107-115.

Caruso, M., Fiore, C., Contursi, M., Salzano, G., Paparella, A. \& Romano, P., 2002. Formation of biogenic amines as criteria for the selection of wine yeasts. World J. Microbiol. Biotechnol. 18, 159-163.

Castelli, T., 1955. Yeasts of wine fermentations from various regions of Italy. Am. J. Enol. Vitic. 6, 18-20.

Castor, J.G.B., 1954. Fermentation products and flavor profiles of yeasts. Wines Vines 35, 29-31.

Charoenchai, C., Fleet, G.H., Henchke, P.A. \& Todd, B.E.N., 1997. Screening of non-Saccharomyces wine yeasts for the presence of extracellular hydrolytic enzymes. Aust. J. Grape Wine Res. 3, 2-8.

Charpentier, C., Nguyen Van Long, T., Bonaly, R. \& Feuillat, M., 1986. Alteration of cell wall structure in Saccharomyces cerevisiae and Saccharomyces bayanus during autolysis. Appl. Microbiol. Biotechnol 24, 405-413.

Ciani, M. \& Ferraro, L., 1998. Combined use of immobilized Candida stellata cells and Saccharomyces cerevisiae to improve the quality of wines. J. Appl. Microbiol. 85, 247-254.

Ciani, M. \& Maccarelli, F., 1998. Oenological properties of non-Saccharomyces yeasts associated with wine-making. World J. Microbiol. Biotechnol. 14, 199-203.

Ciani, M. \& Picciotti, G., 1995. The growth kinetics and fermentation behaviour of some non-Saccharomyces yeasts associated with wine-making. Biotechnol. Lett. 17, 1247-1250.

Clemente-Jimenez, J.F., Mingorance-Cazorla, L., Martínez-Rodríguez, S., Las Heras-Vázquez, F.J. \& Rodríguez-Vico, F., 2004. Molecular characterization and oenological properties of wine yeasts isolated during spontaneous fermentation of six varieties of grape must. Food Microbiol. 21, 149-155. 
Clemente-Jimenez, J.F., Mingorance-Cazorla, L., Martínez-Rodríguez, S., Las Heras-Vázquez, F.J. \& Rodríguez-Vico, F., 2005. Influence of sequential yeast mixtures on wine fermentation. Int. J. Food Microbiol. 98, 301-308.

Cocolin, L., Bisson, L.F. \& Mills, D.A., 2000. Direct profiling of the yeast dynamics in wine fermentations. FEMS Microbiol. Lett. 189, 81-87.

Combina, M., Elía, A., Mercado, L., Catania, C., Ganga, A. \& Martinez, C., 2005. Dynamics of indigenous yeast populations during spontaneous fermentation of wines from Mendoza, Argentina. Int. J. Food Microbiol. 99, 237-243.

Comitini, F., De, J.I., Pepe, L., Mannazzu, I. \& Ciani, M., 2004. Pichia anomala and Kluyveromyces wickerhamii killer toxins as new tools against Dekkera/Brettanomyces spoilage yeasts. FEMS Microbiol. Lett. 238, 235-240.

Constantí, M., Poblet, M., Arola, L., Mas, A. \& Guillamón, J.M., 1997. Analysis of yeast populations during alcoholic fermentation in a newly established winery. Am. J. Enol. Vitic. 48, 339-344.

Constantí, M., Reguant, C., Poblet, M., Zamora, F., Mas, A. \& Guillamón, J., 1998. Molecular analysis of yeast population dynamics: Effect of sulphur dioxide and inoculum on must fermentation. Int. J. Food. Microbiol. 41, 169-175.

Darriet, P., Tominaga, T., Lavigne, V., Boidron, J.-N. \& Durbourdieu, D., 1995. Identification of a powerful aromatic compound of Vitis vinifera L. va. Sauvignon wines: 4-mercapto-4-methylpentan-2-one. Flav. Frag. J. 10, 385-392.

De Cos, P.S.S., Ponsjoán, S.G. \& Cristellys, E.C., 1999. Isolation and identification of the yeast biota in the D.O. Valle de la Orotava (1st part). Vitic. Enol. Sci. $54,21-25$.

De Silóniz, M-I., Balsalobre, L., Alba, C., Valderrama, M.J. \& Peinado, J.M., 2002. Feasibility of copper uptake by the yeast Pichia guilliermondii isolated from sewage sludge. Res. Microbiol. 153, 173-180.

Dizy, M. \& Bisson, L.F., 2000. Proteolytic activity of yeast strains during grape juice fermentation. Am. J. Enol. Vitic. 51, 155-167.

Douglas, L. J., 2003. Candida biofilms and their role in infection. Trends Microbiol. 11, 30-36

Dubourdieu, D., 1996. The aroma of Sauvignon: improvement by winemaking. Rev. Oenol. Tech. Vitivin. Oenol. 79, 18-20 [Fr].

Du Plessis, L. de W., 1959. A study of micro-organisms associated with the flowers and ripening berries of a number of grape varieties. MSc thesis, University of Stellenbosch, South Africa.

Du Toit, W.J., Pretorius, I.S. \& Lonvaud-Funel, A., 2005. The effect of sulfur dioxide on the viability and culturability of Acetobacter pasteurianus and Brettanomyces bruxellensis in wine. J. App. Microbiol. 98, 862-871.

Egli, C.M., Edinger, W.D., Mitrakul, C.M. \& Henick-Kling, T., 1998. Dynamics of indigenous and inoculated yeast populations and their effect on the sensory character of Riesling and Chardonnay wines. J. Appl. Microbiol. 85, 779-789.

Epifanio, S.I., Gutierrez, A.R., Santamaria, M.P. \& López, R., 1999. The influence of enological practices on the selection of wild yeast strains in spontaneous fermentation. Am. J. Enol. Vitic. 50, 219-224.

Erten, H. \& Campbell, I., 2001. The production of low-alcohol wines by aerobic yeasts. J. Inst. Brew. 107, 207-215.

Eschenbruch, R. \& Wong, M., 1993. The use of Brettanomyces and apiculate yeasts in redwine making. In: Lemperle, E. (ed.). Proc. 10th Int. Oenol. Symp., 3-5 May 1993, Montreux, France. International Association for Winery Technology and Management. pp. 268-275.

Fernández-González, M., Di Stefano, R. \& Briones, A., 2003. Hydrolysis and transformation of terpene glycosides from muscat must by different yeast species. Food Microbiol. 20, 35-41.

Fernández, M., Ubeda, J.F. \& Briones, A.I., 2000. Typing of non-Saccharomyces yeasts with enzyme activities of interest in winemaking. Int. J. Food Microbiol. 59, 29-36.

Ferraro, L., Fatichenti, F. \& Ciani, M., 2000. Pilot scale vinification process using immobilized Candida stellata cells and Saccharomyces cerevisiae. Process Biochem. 35, 1125-1129.

Fleet, G.H., 1990. Which yeast species really conducts the fermentation? In: Williams, P.J. Davidson, D.M. \& Lee, T.H. (eds). Proc. 7th Aust. Wine Ind. Tech. Conf., 13-17 August 1989. Australian Wine Research Institute. Winetitles, Adelaide, Australia. pp. 153-156.
Fleet, G.H., 1993. The microorganisms of winemaking - isolation, enumeration and identification. In: Fleet, G.H. (ed). Wine microbiology and biotechnology. Harwood Academic Publishers, Switzerland. pp. 1-25.

Fleet, G.H., 2003. Yeast interactions and wine flavour (review article). Int. J. Food. Microbiol. 86, 11-22.

Fleet, G.H., Lafon-Lafourcade, S. \& Ribéreau-Gayon, P., 1984. Evolution of yeasts and lactic acid bacteria during fermentation and storage of Bordeaux Wines. Appl. Environ. Microbiol. 48, 1034-1038.

Fowell, R.R., 1965. The identification of wild yeast colonies on lysine agar. J. Appl. Bact. 28, 373-383.

Frezier, V. \& Dubourdieu, D., 1992. Ecology of yeast strain Saccharomyces cerevisiae during spontaneous fermentation in a Bordeaux winery. Am. J. Enol. Vitic. $43,375-380$.

Gafner, J., Hoffmann, P., Schütz, M. \& Iselin, F., 1996. Changes of the yeast microflora in the vineyard and during the fermentation. In: Lemperle, E., Trogus, H. \& Figlestahler, P. (eds). Proc. 11th Int. Oenol. Symp., Sopron, Hungary, 3-5 June 1996. pp. 42-54.

Gafner, J., Hoffmann-Boller, P., Porret, N.A. \& Pulver, D. 2000. Restarting sluggish and stuck fermentations. Paper: 2nd International Viticulture and Enology Congress, 8-10 November, Cape Town, South Africa.

Gao, C. \& Fleet. G.H., 1988. The effects of temperature and $\mathrm{pH}$ on the ethanol tolerance of wine yeasts, Saccharomyces cerevisiae, Candida stellata and Kloeckera apiculata. J. Appl. Bacteriol. 65, 405-409.

Gao, C. \& Fleet, G.H., 1995. Degradation of malic and tartaric acids by high density cell suspensions of wine yeasts. Food Microbiol. 12, 65-71.

Gil, J.V., Mateo, J.J., Jimenez, M., Pastor, A. \& Huerta, T., 1996. Aroma compounds in wines as influenced by apiculate yeasts. J. Food Sci. 61, 1247-1249, 1266.

Goodrich, R.J., Braddock, M.E., Parish, M.E. \& Sims, C.A., 1998. Bioconversion of citrus aroma compounds by Pichia pastoris. J. Food Sci. 63, 445-449.

Granchi, L., Ganucci, D., Messini, A., Rosellini, D. \& Vicenzini, M., 1998. Dynamics of yeast populations during the early stages of natural fermentations for the production of Brunello de Montalcino wines. Food Technol. Biotechnol. 36, 313-318

Grbin, P.R., 1999. Are indigenous yeast that important to wine production? Aust. Grapegrow. Winemaker 427, 42-43.

Grbin, P.R., Costello, P.J., Herderich, M., Markides, A.J., Henschke, P.A. \& Lee, T.H., 1995. Developments in the sensory, chemical and microbiological basis of mousy taint in wine. In: Stockley, C.S., Sas, A.N., Johnstone, R.S. \& Lee, T.H. (eds). Proc. 9th Aust. Wine Ind. Tech. Conf., 16-19 July 1995, Adelaide, Australia. pp. 57-61.

Grbin P.R. \& Henschke, P.A., 2000. Mousy off-flavour production in grape juice and wine by Dekkera and Brettanomyces yeasts. Aust. J. Grape Wine Res. 6, 255262.

Greuter, W., Barrie, F.R., Burdet, H.M., Chaloner, W.G., Demoulin, V., Hawksworth, D.L., Jorgenson, P.M., Nicholson, D.H., Silva, P.C., Trehane, P. \& McNeil, J. (eds), 1994. International Code for Botanical Nomenclarture. Koeltz Scientific Books, Königstein.

Guerra, E., Sordi, G., Mannazzu, I., Clementi, F. \& Fatichenti, F., 1999. Occurrence of wine yeasts on grapes subjected to different pesticide treatments. It. J. Food Sci. 11, 221-230.

Guth, H., 1997. Identification of character impact odorants of different white wine varieties. J. Agric. Food Chem. 45, 3022-3026.

Hansen, E.H., Nissen, P., Sommer, P., Nielsen, J.C. \& Arneborg, N., 2001. The effect of oxygen on the survival of non-Saccharomyces yeasts during mixed culture fermentations of grape juice with Saccharomyces cerevisiae. J. Appl. Microbiol. 91, 541-547.

Heard, G., 1999. Novel yeasts in winemaking - looking to the future. Food Aus. $51,347-352$.

Heard, G.M. \& Fleet, G.H., 1985. Growth of natural yeast flora during the fermentation of inoculated wines. Appl. Environ. Microbiol. 50, 727-728.

Heard, G.M. \& Fleet, G.H., 1986. Evaluation of selective media for enumeration of yeasts during wine fermentation. J. Appl. Bact. 60, 477-481. 
Heard, G.M. \& Fleet, G.H., 1988. The effects of temperature and $\mathrm{pH}$ on the growth of yeast species during the fermentation of grape juice. J. Appl. Bacteriol. $65,23-28$.

Henick-Kling, T., Edinger, W., Daniel, P. \& Monk, P., 1998. Selective effects of sulfur dioxide and yeast starter culture addition on indigenous yeast populations and sensory characteristics of wine. J. Appl. Microbiol. 84, 865-876.

Henschke, P.A., 1990. Evaluating wine yeasts for improved wine quality. In: Williams, P.J., Davidson, D.M. \& Lee, T.H. (eds). Proc. 7th Aust. Wine Ind. Tech. Conf., August 1989, Adelaide, Australia. pp. 157-165.

Henschke, P.A., 1997. Wine yeast. In: Zimmermann, K.K. \& Entian, K-D. (eds). Yeast sugar metabolism - biochemistry, genetics, biotechnology and applications. Technomic Publishing Co. Inc., Lanacaster, Pennsylvania, USA. pp. 527-560.

Heresztyn, T., 1986. Formation of substituted tetrahydropyridines by species of Brettanomyces and Lactobacillus isolated from mousy wines. Am. J. Enol. Vitic. $37,127-132$

Herraiz, T., Reglero, G., Herraiz, M., Martin-Alvarez, P.J. \& Cabezudo, M.D., 1990. The influence of the yeast and type of culture on the volatile composition of wines fermented without sulfur dioxide. Am. J. Enol. Vitic. 41, 313-318.

Howell, K.S., Swiegers, J.H., Elsey, G.M., Siebert, T.E., Bartowsky, E.J., Fleet, G.H., Pretorius, I.S., 2004. Variation in 4-mercapto-4-methyl-pentan-2-one release by Saccharomyces cerevisiae commercial wine strains. FEMS Microbiol. Lett. 240, 125-129

Huang, C.-J., Lee, S.-L. \& Chou, C.-C., 2001. Production of 2-phenylethanol, a flavor ingredient, by Pichia fermentans L-5 under various culture conditions. Food Res. Int. 34, 277-282

Jackson, R.S., 1994. Wine Science - principles and applications. Academic Press, San Diego.

Jackson, R.S., 2000. Wine Science - principles, pratice, perception. Academic Press, San Diego.

Jolly, N.P., Augustyn, O.P.H. \& Pretorius, I.S., 2003a. The occurrence of nonSaccharomyces yeast strains over three vintages in four vineyards and grape musts from four production regions of the Western Cape, South Africa. S. Afr. J. Enol. Vitic. 24, 35-42.

Jolly, N.P., Augustyn, O.P.H. \& Pretorius, I.S., 2003b. The effect of nonSaccharomyces yeasts on fermentation and wine quality. S. Afr. J. Enol. Vitic. 24, $55-62$

Jolly, N.P., Augustyn, O.P.H. \& Pretorius, I.S., 2003c. The use of Candida pulcherrima in combination with Saccharomyces cerevisiae for the production of Chenin blanc wine. S. Afr. J. Enol. Vitic. 24, 63-69.

Kreger-van Rij, N.J.W., 1984. The yeasts, a taxonomic study (3rd ed). Elsevier Science Publishers, Amsterdam.

Kurtzman, C.P. \& Droby, S., 2001. Metschnikowia fructicola, a new ascosporic yeast with potential for biocontrol of postharvest fruit rots. Syst. Appl. Microbiol. 24, 395-399.

Kurtzman, C.P. \& Fell, J.W., 1998a. Definition, classification and nomenclature of the yeasts. In: Kurtzman, C.P. \& Fell, J.W. (eds). The yeasts, a taxonomic study. Elsevier Science Publishers, Amsterdam.

Kurtzman, C.P. \& Fell, J.W., 1998b. The yeasts, a taxonomic study (4th ed). Elsevier Science Publishers, Amsterdam.

Lachance, M-A. \& Starmer, W.T., 1998. Ecology of yeasts. In: Kurtzman, C.P. \& Fell, J.W. (eds). The yeasts, a taxonomic study. Elsevier Science Publishers, Amsterdam.

Lambrechts, M.G. \& Pretorius, I.S., 2000. Yeast and its importance to wine aroma - a review. S. Afr. J. Enol. Vitic. 21, 97-129.

Lema, C., Garcia-Jares, C., Orriols, I. \& Angulo, L., 1996. Contribution of Saccharomyces and non-Saccharomyces populations to the production of some components of Albariño wine aroma. Am. J. Enol. Vitic. 47, 206-216.

Le Roux, G., Eschenbruch, R. \& de Bruin, S.I., 1973. The microbiology of South African wine-making. Part VIII. The microflora of healthy and Botrytis cinerea infected grapes. Phytophylactica 5, 51-54.

Longo, E., Cansado, J., Agrelo, D. \& Villa, T.G., 1991. Effect of climatic conditions on yeast diversity in grape musts from Northwest Spain. Am. J. Enol. Vitic. $42,141-144$

Lorenzini, F., 1999. Spontaneous fermentation on red vintage: example with Pinot noir. Revue Suisse de Viticulture, Arboriculture. Hort. 31, 191-195.
Lonvaud-Funel, A., 1996. Microorganisms of winemaking. Cerevisia: Belgian J. Brew. Biotechnol. 21, 55-58

Loureiro, V. \& Malfeito-Ferreira, M., 2003. Spoilage yeasts in the wine industry (review). Int. J. Food Microbiol. 86, 23-50.

Margalith, P.Z., 1981. Flavor microbiology. Charles C. Thomas Publisher, Springfield, USA.

Martens, H., Iserentant, D. \& Verachtert, H., 1997. Microbiological aspects of a mixed yeast-bacterial fermentation in the production of a special Belgian acidic ale. J. Inst. Brew. 103, 85-91.

Martini, A., Ciani, M. \& Scorzetti, G., 1996. Direct enumeration and isolation of wine yeasts from grape surfaces. Am. J. Enol. Vitic. 47, 435-440.

Martini, A., Frederici, F. \& Rosini, G., 1980. A new approach to the study of yeast ecology of natural substances. Can. J. Microbiol. 26, 856-859.

Masih, E.I., Slezack-Deschaumes, S., Marmaras, I., Ait Barka, E., Vernet, G., Charpentier, C., Adholeya, A. \& Paul, B., 2001. Characterisation of the yeast Pichia membranifaciens and its possible use in the biological control of Botrytis cinerea, causing the grey mould disease of grapevine. FEMS Microbiol. Lett. 202, $227-232$

Mateo, J.J., Jimenez, M., Huerta, T. \& Pastor, A., 1991. Contribution of different yeasts isolated from musts of monastrell grapes to the aroma of wine. Int. J. Food Microbiol. 14, 153-160.

Monteil, H., Blazy-Maugen, F. \& Michel, G., 1987. Influence of pesticides on the growth of yeasts from grapes and wine. Sci. Aliments 6, 349-360.

Mora, J. \& Mulet, A., 1991. Effects of some treatments of grape juice on the population and growth of yeast species during fermentation. Am. J. Enol. Vitic. 42, 133-136.

Moreira, N., Mendes, F., Hogg, T. \& Vasconcelos, I., 2005. Alcohols, esters and heavy sulphur compounds production by pure and mixes cultures of apiculate wine yeasts. Int. J. Food Microbiol. 103, 285-294.

Moreno, J.J, Millán, C., Ortega, J.M. \& Medina, M., 1991. Analytical differentiation of wine fermentations using pure and mixed yeast cultures. J. Ind. Microbiol. 7, 181-190.

Mortimer, R. \& Polsinelli, M., 1999. On the origins of wine yeast. Res. Microbiol. $150,199-204$

Nguyen, H-V. \& Panon, G., 1998. The yeast Metschnikowia pulcherrima has an inhibitory effect against various yeast species. Sci. Aliments 18, 515-526.

Nieuwoudt, H.H., Prior, B.A., Pretorius, I.S. \& Bauer, F.F., 2002. Glycerol in South African table wines: an assessment of its relationship to wine quality. S. Afr. J. Enol. Vitc. 23, 22-30.

Nissen, P., Nielsin, D. \& Arneborg, N., 2003. Viable Saccharomyces cerevisiae cells at high concentrations cause early growth arrest of non-Saccharomyces yeasts in mixed cultures by a cell-cell contact-mediated mechanism. Yeast 20, 331-341.

Noble, A.C. \& Bursick, G.F., 1984. The contribution of glycerol to perceived viscosity and sweetness in white wine. Am. J. Enol. Vitic 39, 110-112.

Noble, A.C., Arnold, R.A., Buechsenstein, J., Leach, E.J., Schmidt, J.O. \& Stern, P.M., 1987. Modification of a standardized system of wine aroma terminology. Am. J. Enol. Vitic. 38, 134-146.

Nykänen, L., 1986. Formation and occurrence of flavor compounds in wine and distilled alcoholic beverages. Am. J. Enol. Vitic. 37, 84-96.

Obisanya, M.O., Aina, J.O. \& Oguntimein, G.B., 1987. Production of wine from mango (Magnifera indica L.) using Saccharomyces and Schizosaccharomyces species isolated from palm wine. J. Appl. Bacteriol. 63, 191-196.

Ough, C.S. \& Amerine, M.A., 1963. Use of grape concentrate to produce sweet table wines. Am. J. Enol. Vitic. 14, 194-204.

Owuama, C.I. \& Saunders, J.R., 1990. Physiological variants of Saccharomyces cerevisiae and Kloeckera apiculata from palm wine and cashew juice. J. Appl. Bacteriol. 68, 491-494.

Pallmann, C.L., Brown, J.A., Olineka, T.L., Cocolin, L., Mills, D.A. \& Bisson, L.F., 2001. Use of WL medium to profile native flora fermentations. Am. J. Enol. Vitic. 53, 198-203.

Panon, G., 1997. Influence of oxygen on fermentation pattern in model media containing mixed or sequential cultures of three cider-producing yeasts: Saccharomyces cerevisiae, var. uvarum, Hanseniaspora valbyensis and Metschnikowia pulcherrima. Sci. Aliments 17, 193-217. 
Parish, M.E. \& Caroll, D.E., 1985. Indigenous yeasts associated with Muscadine (Vitis rotundifolia) grapes and musts. Am. J. Enol. Vitic. 36, 165-169.

Parsek, M.R. \& Greenberg, E.P., 2005. Sociomicrobiology: the connections between quorum sensing and biofilms. Trends Microbiol. 13, 27-33.

Peynaud, E. \& Domercq, S., 1959. A review of microbiological problems in winemaking in France. Am. J. Enol. Vitic. 10, 69-77.

Pina, C., Santos, C., Couto, J.A. \& Hogg, T., 2004. Ethanol tolerance of five nonSaccharomyces wine yeasts in comparison with a strain of Saccharomyces cerevisiae - influence of different culture conditions. Food Microbiol. 21, 439-447.

Polsinelli, M., Romano, P., Suzzi, G. \& Mortimer, R., 1996. Multiple strains of Saccharomyces cerevisiae on a single grape vine. Lett. Appl. Microbiol. 22, 1-5.

Prakitchaiwattana, C.J., Fleet, G.H. \& Heard, G.M., 2004. Application and evaluation of denaturing gradient gel electrophoresis to analyse the yeast ecology of wine grapes. FEMS Yeast Res. 4, 865-877.

Pretorius, I.S., Van der Westhuizen, T.J. \& Augustyn, O.P.H., 1999. Yeast biodiversity in vineyards and wineries and its importance to the South African wine industry. S. Afr. J. Enol. Vitic. 20, 61-74.

Pretorius, I.S., 2000. Tailoring wine yeast for the new millennium: novel approaches to the ancient art of winemaking. Yeast 16, 675-729.

Pretorius, I.S., 2003. The genetic analysis and tailoring of wine yeasts. In: De Winde, J.H. (ed). Topics in current genetics, vol 2. Springer-Verlag, Berlin. pp. 99-141.

Prior, B.A., Toh, T.H., Jolly, N., Baccari, C.L. \& Mortimer, R.K., 2000. Impact of yeast breeding for elevated glycerol production on fermentation activity and metabolite formation in Chardonnay. S. Afr. J. Enol. Vitic. 21, 92-99.

Querol, A., Jiménez, M. \& Huerta, T., 1990. Microbiological and enological parameters during fermentation of musts from poor and normal grape harvests in the region of Alicante (Spain). J. Food Sci. 55, 1603-1606.

Radler, F. \& Schütz, H., 1982. Glycerol production of various strains of Saccharomyces. Am. J. Enol. Vitic. 33, 36-40.

Rankine, B.C., 1972. Influence of yeast strain and malo-lactic fermentation on composition and quality of table wines. Am. J. Enol. Vitic. 23, 152-158.

Rauhut, D., 1993. Yeasts - production of sulphur compounds. In: Fleet, G.H. (ed). Wine microbiology and biotechnology. Harwood Academic Publishers, Switzerland. pp. 183-223.

Reed, G. \& Peppler, H.J., 1973. Yeast Technology. The AVI Publishing Company, Inc., Connecticut.

Regueiro, L.A., Costas, C.L. \& Rubio, J.E.L., 1993. Influence of viticultural and enological practices on the development of yeast populations during winemaking. Am. J. Enol. Vitic. 44, 405-408.

Rementeria, A., Rodriguez, J.A., Cadaval, A., Amenabar, R., Muguruza, J.R., Hernando, F.L. \& Sevilla, M.J., 2003. Yeast associated with spontaneous fermentations of white wines from the "Txakoli de Bizkaia" region (Basque Country, North Spain). Int. J. Food Microbiol. 86, 201-207.

Renouf, V., Claisse, O. \& Lonvaud-Funel, A., 2005. Understanding the microbial ecosystem on the grape berry surface through numeration and identification of yeast and bacteria. Aust. J. Grape Wine Res. 11, 316-327.

Reynolds, T.B. \& Fink, G.R., 2001. Bakers' yeast, a model for fungal biofilm formation. Sci. 291, 878-881.

Ribéreau-Gayon, P., Glories, Y., Maujean, A. \& Dubourdieu, D., 2000. Handbook of enology (vol. 2). John Wiley \& Sons Ltd., Chichester. pp.187-206.

Rodriguez, M.E., Lopez, C.A., Broock, M., Valles, S., Ramon, D. \& Caballero, A.C., 2004. Screening and typing of Patagonian wine yeasts for glycosidase activities. J. Appl. Microbiol. 96, 84-95.

Rojas, V., Gil, J.V., Piñaga, F. \& Manzanares, P., 2003. Acetate ester formation in wine by mixed cultures in laboratory fermentations. Int. J. Food Microbiol. 86, 181-188.

Romano, P., Fiore, C., Paraggio, M., Caruso, M. \& Capece, A., 2003. Function of yeast species and strains in wine flavour. Int. J.Food Microbiol. 86, 169-180.

Romano, P., Marchese, Laurita, C., Saleano, G. \& Turbanti, L., 1999. Biotechnological suitability of Saccharomycodes ludwigii for fermented beverages. World J. Microbiol. Biotech. 15, 451-454.

Romano, P. \& Suzzi, G., 1993a. Potential use for Zygosaccharomyces species in winemaking. J. Wine Res. 4, 87-94.
Romano, P. \& Suzzi, G., 1993b. Higher alcohol and acetoin production by Zygosaccharomyces wine yeasts. J. Appl. Bact. 75, 541-545.

Romano, P. \& Suzzi, G., 1996. Origin and production of acetoin during wine yeast fermentation (mini review). Appl. Environ Microbiol. 62, 309-315.

Romano, P., Suzzi, G., Comi, G. \& Zironi, R., 1992. Higher alcohol and acetic acid production by apiculate wine yeasts. J. Appl. Bact. 73, 126-130.

Romano, P., Suzzi, G., Comi, G., Zironi, R. \& Maifreni, M., 1997. Glycerol and other fermentation products of apiculate wine yeasts. J. Appl. Microbiol. 82, 615-618.

Romano, P., Suzzi, G., Zironi, R. \& Comi, G., 1993. Biometric study of acetoin production in Hanseniaspora guilliermondii and Kloeckera apiculata. Appl. Environ. Microbiol. 59, 1838-1841.

Rosi, I., Vinella, M. \& Domizio, P., 1994. Characterization of $\beta$-glucosidase activity in yeasts of oenological origin. J. Appl. Bact. 77, 519-527.

Rosini, G., 1984. Assessment of dominance of added yeast in wine fermentation and origin of Saccharomyces cerevisiae in wine-making. J. Gen. Appl. Microbiol. $30,249-256$

Rosini, G., Federici, F. \& Martini, A., 1982. Yeast flora of grape berries during ripening. Microb. Ecol. 8, 83-89.

Scanes, K.T., Hohmann, S. \& Prior, B.A., 1998. Glycerol production by the yeast Saccharomyces cerevisiae and its relevance to wine: a review. S. Afr. J. Enol. Vitic. 19, 15-21.

Schmitt, M.J. \& Breinig, F., 2002. The viral killer system in yeast: from molecular biology to application. FEMS Microbiol. Rev. 26, 257-276.

Schütz, M. \& Gafner, J., 1993. Analysis of yeast diversity during spontaneous and induced alcoholic fermentations. J. Appl. Bact. 75, 551-558.

Sharf, R. \& Margalith, P., 1983. The effect of temperature on spontaneous wine fermentation. Eu. J. Appl. Microbiol. Biotechnol. 17, 311-313.

Soden, A., Francis, I.L., Gockowiak, H., Lee, T.H. \& Henschke, P.A., 1998. The use of non-Saccharomyces yeasts in winemaking. In: Blair, R.J., Sas, A.N., Hayes, P.F. \& Høj, P.B. (eds). Proc. 10th Aust. Wine Ind. Tech. Conf., 2-5 August 1998, Sydney, Australia. pp. 166-171

Soden, A., Francis, I.L., Oakey, H. \& Henschke, P.A., 2000. Effects of co-fermentation with Candida stellata and Saccharomyces cerevisiae on the aroma and composition of Chardonnay wine. Aust. J. Grape Wine Res. 6, 21-30.

Soles, R.M., Ough, C.S. \& Kunkee, R.E., 1982. Ester concentration differences in wine fermented by various species and strains of yeast. Am. J. Enol. Vitic. 33, 94-98.

Spagna, G., Barbagallo, R.N., Palmeri, R., Restuccia, C. and Giudici, P., 2002. Properties of endogenous $\beta$-glucosidase of a Pichia anomala strain isolated from Sicilian musts and wines. Enzyme Microb. Technol. 31, 1036-1041.

Strauss, M.L.A., Jolly, N.P., Lambrechts, M.G. \& Van Rensburg, P., 2001. Screening for the production of extracellular hydrolytic enzymes by nonSaccharomyces wine yeasts. J. Appl. Microbiol. 91, 182-190.

Suomalainen, H. \& Lehtonen, M., 1979. The production of aroma compounds by yeast. J. Inst. Brew. 85, 149-156.

Sütterlin, K.A., Hoffmann-Boller, P. \& Gafner, J., 2004. Kurieren von gärstockungen mit der fructophilen weinhefe Zygosaccharomyces bailii. Poster: 7th International Symposium on Innovations in Enology, Intervitis Interfructa 2004, 10-11 May, Stuttgart-Killesberg, Germany.

Swiegers, J.H., Bartowsky, E.J., Henschke, P.A. \& Pretorius, I.S., 2005. Yeast and bacterial modulation of wine aroma and flavour. Aust. J. Grape Wine Res. 11, 139-173

Swiegers, J.H. \& Pretorius, I.S., 2005. Yeast modulation of wine flavour. Adv. Appl. Microbiol. 57, 131-175.

Teoh, A.L., Heard, G. \& Cox, J., 2004. Yeast ecology of Kombucha fermentation. Int. J. Food Microbiol. 95, 119-126.

Thornton, R.J. \& Rodriguez, S.B., 1996. Deacidification of red and white wines by a mutant Schizosaccharomyces malidevorans under commercial winemaking conditions. Food Microbiol. 13, 475-482.

Todd, B.E.N., 1995. Enhancing the sensory properties of wine using $\beta$-glycosidase activity of wine micro-organisms. Aust. Grapegrow. Winemaker 382, 22-23.

Torija, M.J., Rozés, N., Poblet, M., Guillamon, J.M. \& Mas, A., 2001. Yeast population dynamics in spontaneous fermentations: Comparison between different wine-producing areas over a period of three years. Ant. v. Leeuwen. 79, 345-352. 
Török, T., Mortimer, R.K., Romano, P., Suzzi, G. \& Polsinelli, M., 1996. Quest for wine yeasts - an old story revisited. J. Indust. Microbiol. 17, 303-313.

Ubeda-Iranzo, J.F., Briones-Perez, A.I. \& Izquierdo-Canas, P.M., 1998. Study of the oenological characteristics and enzymatic activities of wine yeasts. Food Microbiol. 15, 399-406.

Van der Walt, J.P. \& Van Kerken, A.E., 1958. The wine yeasts of the Cape. I. A taxonomical survey of the yeasts causing turbidity in South African table wines. Wine Industry Research Group, Stellenbosch. South African Council for Scientific Industrial Research, Pretoria.

Van Kerken, A.E., 1963. Contribution to the ecology of yeasts occurring in wine. $\mathrm{PhD}$ thesis, University of the Orange Free State, Bloemfontein, South Africa.

Van Rensburg, P., Stidwell, T., Lambrechts, M.G., Cordero Otero, R.R. \& Pretorius, I.S., 2005. Development and assessment of a recombinant Saccharomyces cerevisiae wine yeast producing two aroma-enhancing $\beta$-glucosidases encoded by the Saccharomycopsis fibuligera BGL1 and BGL2 genes. Anal. Microbiol. 55, 33-42.

Van Zyl, J.A., 1962. Troebeling in Suid-Afrikaanse droëwyne veroorsaak deur die ontwikkeling van die Brettanomyces-giste. Navorsingsinstituut vir Wynbou en Wynbereiding, Stellenbosch. Wetenskaplike pamflet no. 381, Departement van Landbou-Tegniese Dienste, Pretoria.

Van Zyl, J.A. \& Du Plessis, L. de W., 1961. The microbiology of South African winemaking. I. The yeasts occurring in vineyards, must and wines. S. Afr. J. Agric. Sci. 4, 393-403.

Van Zyl, J.A., De Vries, M.J. \& Zeeman, A.S., 1963. The microbiology of South African winemaking. III. The effect of different yeasts on the composition of fermented musts. S. Afr. J. Agric. Sci. 6, 165-179.

Vaughan-Martini, A. \& Martini, A., 1995. Facts, myths and legends on the prime industrial microorganism. J. Indust. Microbiol. 14, 514-522.
Weiler, F. \& Schmitt, M.J., 2003. Zygocin, a secreted antifungal toxin of the yeast Zygosaccharomyces bailii, and its effect on sensitive fungal cells. FEMS Yeast Res. 3, 69-76.

Wenning, M., Seiler, H. \& Scherer, S., 2002. Fourier-transform infrared microspectroscopy, a novel and rapid tool for identification of yeasts. Appl. Environ. Microbiol. 68, 4717-4721.

Yanagida, F., Ichinose, F., Shinohara, T. \& Goto, S., 1992. Distribution of wild yeasts in the white grape varieties at central Japan. J. Gen. Appl. Microbiol. 38, 501-504

Yanai, T. \& Sato, M., 1999. Isolation and properties of $\beta$-glucosidase produced by Debaryomyces hansenii and its application in winemaking. Am. J. Enol. Vitic. 50, 231-235.

Yap, A.S.J., 1987. Development of new yeast strains for winemaking. Aust. Grapegrow. Winemaker 287, 19-21.

Yarrow, D., 1998. Methods for the isolation, maintenance and identification of yeasts. In: Kurtzman, C.P. \& Fell, J.W. (eds). The yeasts, a taxonomic study. Elsevier, Amsterdam.

Zahavi, T., Droby, S., Cohen, L., Weiss, B. \& Ben-Arie, R., 2002. Characterisation of the yeast flora on the surface of grape berries in Israel. Vitis 41, 203-308.

Zironi, R., Romano, P., Suzzi, G., Battistutta, F. \& Comi, G., 1993. Volatile metabolites produced in wine by mixed and sequential cultures of Hanseniaspora guilliermondii or Kloeckera apiculata and Saccharomyces cerevisiae. Biotechnol. Lett. 15, 235-238.

Zohre, D.E. \& Erten, H., 2002. The influence of Kloeckera apiculata and Candida pulcherrima yeasts on wine fermentation. Process Biochem. 38, 319-324. 